Journal of Systems Science and Information

Feb., 2021, Vol. 9, No. 1, pp. 16-44

DOI: $10.21078 /$ JSSI-2021-016-29

\title{
Big Data Analytics in E-commerce for the U.S. and China Through Literature Reviewing
}

\author{
Weiqing ZHUANG \\ School of Internet Economics and Business, Fujian University of Technology, Fuzhou 350108, China; \\ Research Center for "One Belt and Road" Economic and Policy, Fujian University of Technology, \\ Fuzhou 350108, China \\ E-mail:zmakio@aliyun.com \\ Morgan C. WANG \\ College of Science, University of Central Florida, Florida 32525, USA \\ E-mail: Chung-Ching.Wang@ucf.edu \\ Ichiro NAKAMOTO \\ School of Internet Economics and Business, Fujian University of Technology, Fuzhou 350108, China \\ E-mail: 2910016801@qq.com \\ Ming JIANG* \\ School of Internet Economics and Business, Fujian University of Technology, Fuzhou 350108, China \\ E-mail: 535688191@qq.com
}

\begin{abstract}
Big data analytics (BDA) in e-commerce, which is an emerging field that started in 2006, deeply affects the development of global e-commerce, especially its layout and performance in the U.S. and China. This paper seeks to examine the relative influence of theoretical research of BDA in e-commerce to explain the differences between the U.S. and China by adopting a statistical analysis method on the basis of samples collected from two main literature databases, Web of Science and CNKI, aimed at the U.S. and China. The results of this study help clarify doubts regarding the development of China's e-commerce, which exceeds that of the U.S. today, in view of the theoretical comparison of BDA in e-commerce between them.
\end{abstract}

Keywords big data analytics; e-commerce; U.S. and China; literature review

\section{Introduction}

With the increasing cooperation and competition between the United States and China, especially considering the outbreak of $\mathrm{S} \& \mathrm{~T}$ and trade war, increasingly more attention has been paid to comparison between the United States and China's big data analytics (BDA) in

Received May 11, 2020, accepted June 25, 2020

Supported by the Ministry of Education's Humanities and Social Sciences Research Project (18YJAZH153); Fujian Natural Science Foundation (2018J01648); Fujian Social Sciences Federation Planning Project (FJ2018B032); Development Fund of Scientific Research from Fujian University of Technology (GY-S18109)

* Corresponding author 
application. It comprehensively and systematically compares the relevant literature for BDA in e-commerce between U.S. and China, collected by two main literature databases, Web of Science and CNKI respectively aim at U.S. and China, during the period from 1990 to 2017. Before analyzing, the overall academic research of U.S. and China in related subjects of big data and e-commerce need to be introduced first, and as the foundation of BDA, comparison of research situation in business intelligence and analytics, and models and algorithms of BDA, are also presented between U.S. and China; Next, BDA in e-commerce is discussed around trends in e-commerce research, online consumer behavior, internet of things in e-commerce, mobile technology in e-commerce, cloud computing in e-commerce, and artificial intelligence in e-commerce; Finally, a brief prospect is given.

\section{Overall Research in the U.S. and China}

As a whole, we present the results of three stages of searching for subject terms classified by title $^{1}$ from several literature databases in Table A1. The first stage retrieves the term 'Electronic Commerce' or 'Electronic Business' from databases, including the Web of Science (abbr. WoS), ProQuest, EBSCOhost, JSTOR, EI Engineering Village, and ACM Digital Library from the U.S. and CNKI from China. The second stage is retrieval of the term 'big data' so that searching for 'Electronic Commerce' or 'Electronic Business' retrieve the term 'Big Data Analytics'. Then, if the comparison of some of the U.S. literature databases with China's CNKI is not very different, then it is concluded that China, similar to the U.S., has shown great interest and paid great attention to Electronic Commerce. For instance, searching 'e-commerce' and 'Big Data' in CNKI (All) retrieves 85 documents that concentrate on e-commerce and Big Data from a group of 13,072 papers, and the proportion is 0.65 percent, which is higher than that of the WoS, 0.59 percent, and others. However, this search finds that WoS at 0.61 percent is higher than CNKI (All), 0.54 percent, as shown in Table A2. Compared with more similar literature databases, CNKI (All) and EI Engineering Village, in four cases of searching for the subject terms, the proportion of retrieve papers that concentrate on e-commerce and big data from CNKI (All) is 0.52 percent, higher than that from EI Engineering Village, 0.28 percent. According to Master's and doctoral dissertations, it is obvious that China puts more effort into e-commerce using BDA research as well.

To further observe the change of the quantity of the literature from the U.S. and China's databases yearly, different characteristics of research activities on e-commerce using BDA between the U.S. and China are described in Table A2, Figure 1, and Figure 2. The study of e-commerce dates back to 1995; after four years, it developed very rapidly to approximately 7000 papers published every year and during the year of 1999 to 2000 according to the ProQuest database; however, the study output from 2001 to 2010 showed a downward trend until 2011, when it returned to previous levels of growth. In short, research on e-commerce in the U.S. has not drawn extensive attention, which was also found from the WoS database. However, in China, the development of research on e-commerce has been slightly different than that of the

\footnotetext{
${ }^{1}$ Searching subject terms classified by title in the literature in this article is performed because there are a number of papers that are not directly related to count if searching by subject/title/abstract, which would reduce the accuracy of the study.
} 
U.S., with almost the same starting time of research; however, this research has continuously increased in output, much like the trend of the growth of Alibaba, a company founded in 1999 that has constantly and swiftly grown. This process of past research in China may be verified by the development of e-commerce in practice, which is likely somewhat of a correlation of theory and practice and will be analyzed in the next section. The goal of this paper is to explain why China's electronic commerce trade is much more active than that of the U.S. Furthermore, retrieving the terms 'e-commerce' and 'Big Data' from CNKI, regardless of being limited to periodicals or not, shows that there are slightly more papers than in the WoS (Core Collection) and ProQuest. This discrepancy is a serious problem that needs to be faced and resolved in the U.S.

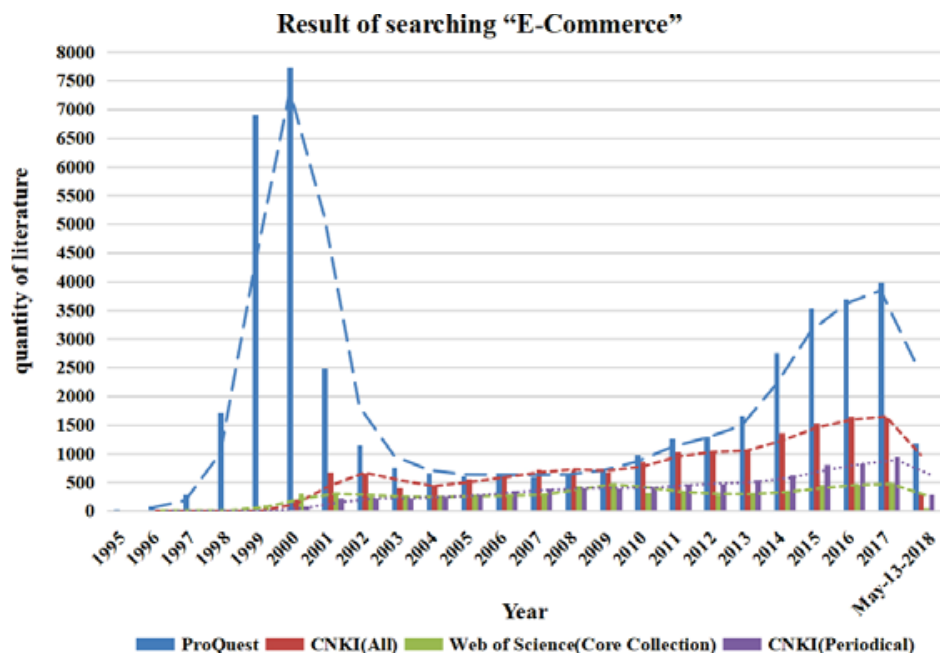

(a)

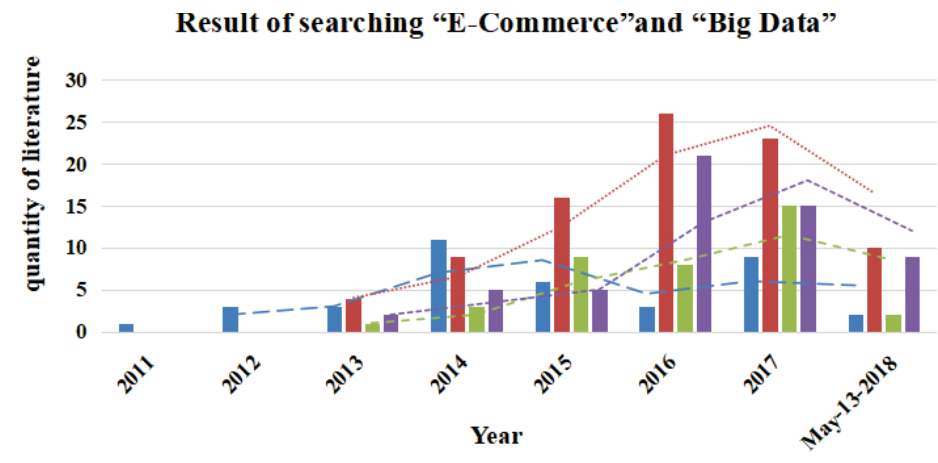

ProQuest $\square$ CNKI (AII) Web of Science (Core Collection) $\square$ CNKI (Periodical)

(b)

Figure 1 (a) Literature quantity retrieved with the 'e-commerce' subject term from U.S. and China databases; (b) Literature quantity retrieved for the 'ecommerce' and 'Big Data' subject terms from U.S. and China databases 


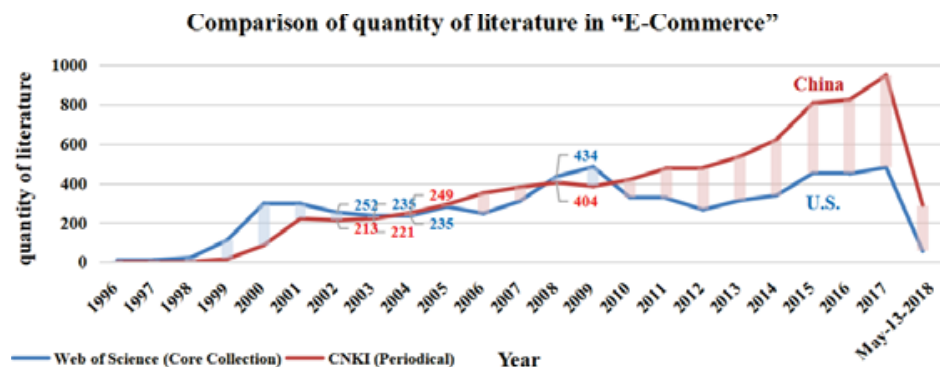

(a)

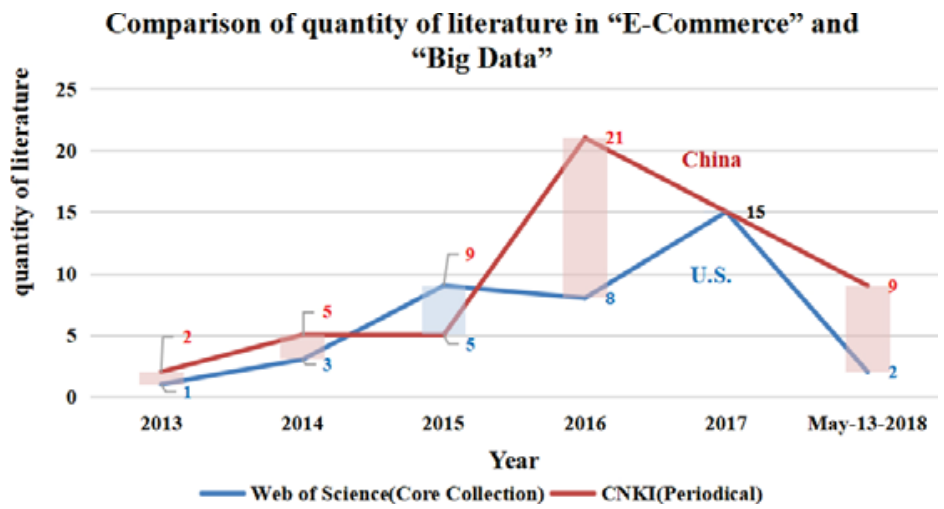

(b)

Figure 2 (a) Comparison of the literature quantity retrieved with the "e-commerce" subject term from U.S. and China databases; (b) Comparison of the literature quantity retrieved for the "e-commerce" and "Big Data" subject terms from U.S. and China databases

\section{Business Intelligence and Analytics}

Business intelligence and analytics (BI\&A) and the related field of big data analytics have become increasingly important in both the academic and the business communities over the past two decades ${ }^{[1]}$. Sun, et al. ${ }^{[2]}$ surveyed data analysis and showed that the proposed big data analytics service-oriented architecture (BASOA) is viable for enhancing BI and enterprise information systems. In the late 2000s, business analytics was introduced to represent the key analytical component in $\mathrm{BI}^{[1,3]}$, and then, in 2005, Andreas, et al. ${ }^{[4]}$ proposed an architecture for enhanced business intelligence that was composed of two infrastructure types, information integration and business integration; this architecture was a real-time analytics technique with the aim of reducing the action time and increasing the value. Successively, several articles ${ }^{[5-13]}$ were published in conference proceedings and so on that were valuable for promoting the correlation of BI\&A and BDA; of course, the data warehouse of BI\&A was not constructed and equipped with the infrastructure of big data that Hadoop has hardened for enterprises ${ }^{[14]}$. Escobedo, et al. ${ }^{[15]}$ used business intelligence and data analytics (BI\&DA) to support the operation of the smart grid, and a combination of BI\&A and BDA and some of the enabling technologies for the future development of such fields have appeared.

Danyel, et al. ${ }^{[16]}$ introduce business intelligence analytics to help users understand and act on widely disparate types of data in a special issue of IEEE CG\&A. Hence, the development 
of big data analytics can be followed and described by the evolution of BI\&A. Until now, the evolution of BI\&A has gone through four phrases: BI\&A 1.0, where data are mostly structured and DBMS-Based; BI\&A 2.0, for unstructured and web-based approaches; BI\&A 3.0, which presented a new era of mobile and sensor-based approaches ${ }^{[1]}$; and BI\&A 4.0, which is ultraintelligent and allows optimal decisions to be made automatically as well as combines physical and virtual data; BI\&A 4.0 can be referred to as an artificial intelligence-based approach ${ }^{[17]}$. In addition, business analytics can be divided into three main components: Descriptive analytics, predictive analytics and prescriptive analytics ${ }^{[18]}$. While some organizations recognize and exploit the benefits of business intelligence and analytics use ${ }^{[19]}$, others fail to capitalize on their potential ${ }^{[20]}$ because their deployment is complex, expensive, time consuming and laden with risk $^{[21-23]}$. Therefore, research on analytics and big data is still in its nascent stage, and academics and practitioners are involved in developing new algorithms as well as applying existing algorithms to solve new problems ${ }^{[18]}$.

Regarded as one framework and analysis tool of BDA in e-commerce, the integration of BI and BDA is a necessity to assist decision makers in increasing the efficiency of public services ${ }^{[24]}$. Therefore, a dramatic comparison between on the selected 'WoS (Core Collection)' and 'CNKI (Periodical)', literature databases from the U.S. and China, respectively, shows that in researching business intelligence and analytics, the academic research in this field can be ascertained for the two countries; how much this research has contributed to enterprises that specialize in BDA in e-commerce will be discussed below in this article. The results, as shown in Table A3, present the definite difference of research achievements in BI\&A between the U.S. and China. Until 28 May 2018, there was a total number of 63 papers in the WoS, in which the direct research work started in 2005 and proceeded indifferently afterwards, but since 2014, this research has shown a large increase, from a few papers to over a dozen papers per year, which implies that not only academic research but also applications of BI\&A have been widely considered as important in the U.S. over the past three years. However, in China, this research proceeded inconspicuously from the past to the present, even though it began early in 2001.

More specifically, following the comparison presented in Table A4, the U.S. pays more attention to creating a new theoretical framework of the combination of $\mathrm{BI}$ and BDA ${ }^{[25-27]}$ than China, and the technical exploitation and discussion of BI also surpass those in China. Apparently, this result clearly indicates that the U.S. goes further in using BDA to support business intelligence in e-commerce both in theory and application.

\section{Models and Algorithms of Big Data Analytics}

Over the past decade, we have witnessed the unfolding of the Internet of Things, advancements in machine learning, and technological breakthroughs in areas including robotics, artificial intelligence, virtual reality, autonomous vehicles, facial recognition, medical diagnostics, and fraud detection ${ }^{[47]}$. The potential advantages of utilizing these data have been broadly recognized ${ }^{[48]}$, and the exponential creation of data by new data generating sources has gained attention from businesses, governments, and academia through efforts to harness and analyze big data ${ }^{[49]}$. In the book with the refereed conference proceedings of the Fourth International Conference on Big Data Analytics (BDA 2015) ${ }^{[50]}$, some of the representative papers introduce a 
wide range of algorithms for BDA, including Raj's ${ }^{[51]}$ completely new rethink of the MapReduce paradigm, Masashi's ${ }^{[52]}$ mobility big data analysis and visualization, Kiran's ${ }^{[53]}$ periodic pattern mining in analyzing e-commerce behaviors, Surbhi's ${ }^{[54]}$ VDMR-DBSCAN (varied density MapReduce DBSCAN), Goel's ${ }^{[55]}$ formal concept analysis (FCA), Astha's ${ }^{[56]} \alpha$-miner algorithm, and Arpita's ${ }^{[57]}$ proposed algorithm, etc. To understand the models and algorithms of BDA well, the big data characteristics defined by V's should be made certain.

The first attempt at defining the big data phenomenon was by Laney from the META Group (now Gartner) in 2001 ${ }^{[58]}$. Without mentioning the term explicitly, Laney ${ }^{[59]}$ introduced the concept of the ' $3 \mathrm{Vs}$ ', underpinning the increase in data volume, velocity, and variety. Volume refers to the quantity of data generated at an exponential rate, with data sets ranging from terabytes to zettabytes in size. Velocity relates to the increased speed at which data are available and requires near real-time processing to maximize the value of data. Variety refers to the multiplicity of data types generated from a range of sources, including social networks, mobile phones, traffic cameras, and various sensors ${ }^{[60]}$. However, data are simply raw symbols with no significance beyond their existence, while information is data that have been processed and attributed substantive meaning. Hence, later studies have noted that these data characteristics are insufficient to explain the multifaceted nature of big data ${ }^{[61]}$. Duygu ${ }^{[62]}$ extends the concept to ' $6 \mathrm{Vs}$ ', including other factors such as veracity, which points to the trustworthiness of data; vocabulary, which involves schema, models, and ontologies that describe the data's structure; and value, which refers to insight and cost. Several authors have added features such as veracity $^{[63,64]}$, value ${ }^{[65-67]}$, variability ${ }^{[66]}$, and visualization ${ }^{[1]}$ for a total of '8Vs'. Consequently, big data has become a volatile term that has led to different interpretations ${ }^{[58]}$.

To realize the objectives and functions of these 'Vs', some efficient and effective models and algorithms are needed to handle and analyze big data from various angles, involving the architecture of Hadoop ${ }^{[68-72]}$; approaches to collect, store, process, and clean big data ${ }^{[73-75]}$; big data techniques and applications ${ }^{[76,77]}$; and big data security and privacy ${ }^{[78]}$, etc. Concretely, some key subject terms of big data models and algorithms can be retrieved using the field of 'title' separately in the WoS (U.S.) and CNKI (China). As shown in Table A5 and Figure 3, there are only a few differences between the U.S. and China in carrying out research on big data models or algorithms, with the exception of 'MapReduce', 'Apriori', and 'Cloud and Big Data', etc. These models or algorithms, such as 'k-means', 'SVM', 'machine learning', 'deep learning', 'clustering algorithm', 'cloud', 'regression', 'decision analytics', 'optimization', 'genetic algorithm', 'neural networks', 'text analysis', 'association rules', 'classifier', 'social network', and 'prediction model', were applied to big data shortly after 2010 and will undoubtedly propel prospective applications of big data analytics in the coming years. In Figure 4, a dramatic increase of researchers involved in the models and algorithms of big data analytics in both the U.S. and China is shown, which started around 2010, and the quantity of China's research outputs in some fields has even exceeded that of the U.S. For example, the combination of 'cloud' and big data has grown faster in China than in the the U.S. over the past years, which can be verified by the development status of the 'cloud' and big data industry. 


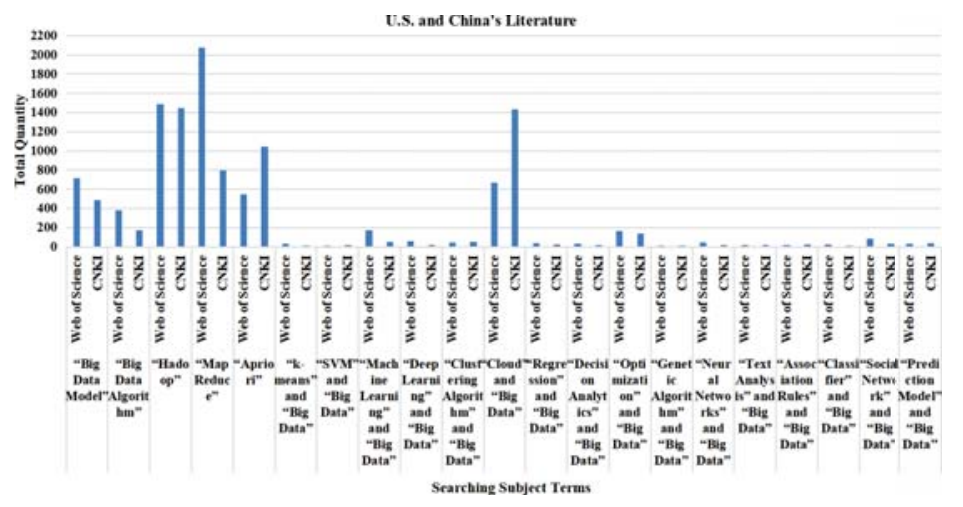

Figure 3 Comparison of the literature from the U.S. and China in terms of the total quantity of big data models and algorithms

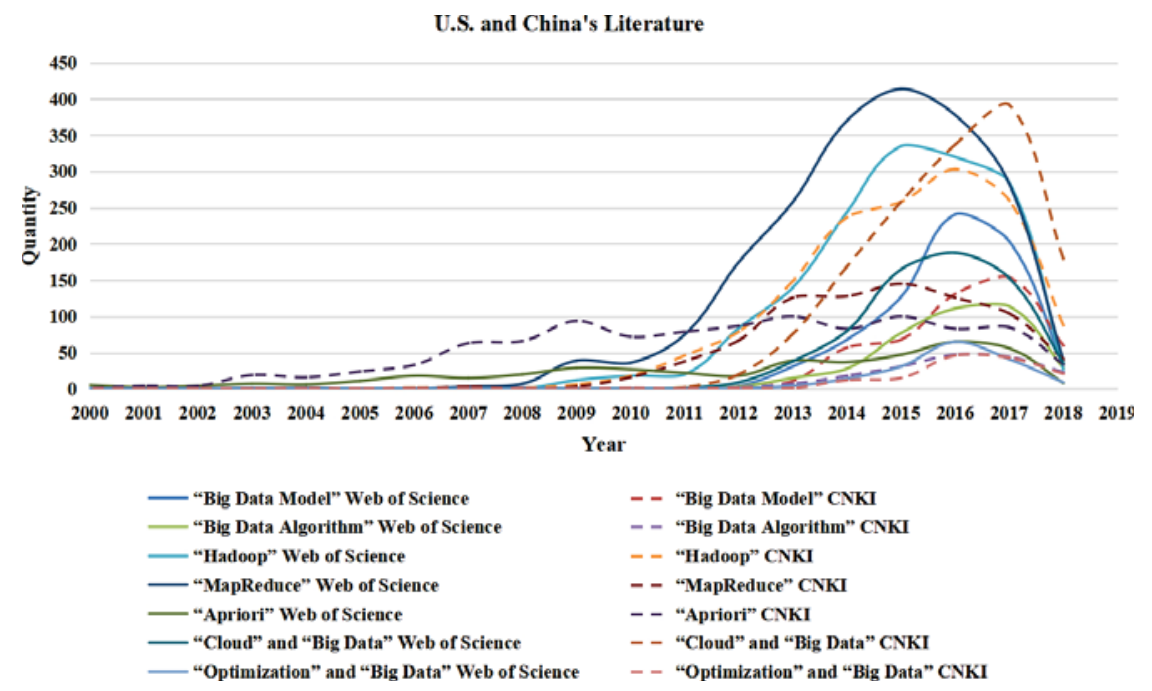

Figure 4 Comparison of the literature from the U.S. and China in terms of the quantity of some big data models and algorithms per year

Whether used in the U.S. or China, big data learning algorithms that can select suitable techniques to manage and analyze dynamically growing massive data sets efficiently and extract useful information ${ }^{[79]}$ represent a continued vital breakthrough area for both countries. To improve big data learning algorithms in the future, for instance, by addressing the remarkable progress of the quantum computing architecture that will perform computations beyond the capabilities of any classical computer (Von Neumann architecture) ${ }^{[34]}$, the framework of big data learning models and algorithms must be explained using the characteristics of the data domain ${ }^{[79]}$ under the classical computing architecture first. Big data learning deals with an environment where the given data are known ${ }^{[79]}$ through various deep learning models and algorithms ${ }^{[80,81]}$, which are made up of the following components: The big data processing system, outlier detection system, feedback mechanism and continuous learning, and the supervised learning module ${ }^{[82]}$, with their corresponding responses shown in Figure 5. 


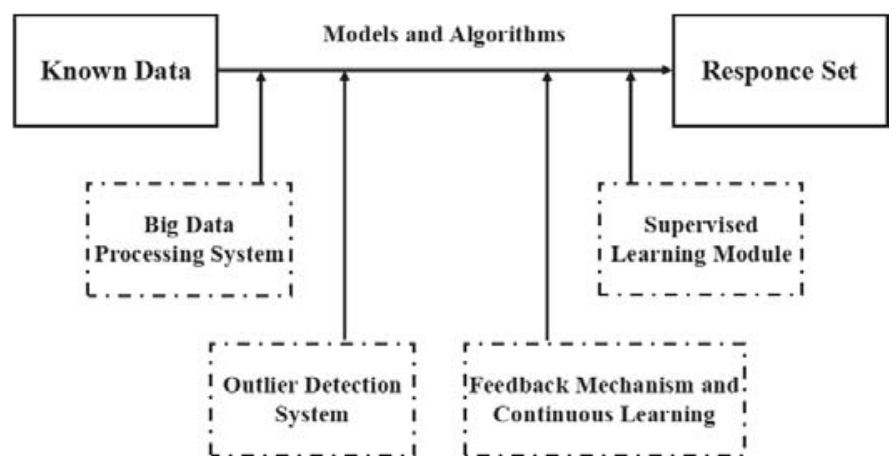

Figure 5 Schematic of big data learning

\section{Big Data Analytics in E-Commerce}

A report from Statista shows that retail e-commerce sales worldwide amounted to 2.3 trillion US dollars in 2017 and that e-retail revenues are projected to grow to 4.88 trillion US dollars in $2021^{2}$. In 2017, in Pacific Asia, e-retail sales accounted for 14.9 percent of retail sales ${ }^{3}$, of which the U.S. accounted for 9 percent $^{4}$ and China accounted for 23.8 percent $^{5}$. With the global e-commerce market continuing to flourish, e-commerce trends, market discipline, trading behaviors, and demand characteristics, etc. are required to have sets of complex technical measures for accurate analyses and predictions in the big data environment. Thus, BDA in e-commerce is becoming a hot issue in academic research but remains poorly-explored as a concept, which obstructs its theoretical and practical development ${ }^{[83]}$. As illustrated in Table A6, it is shown that combining BDA and e-commerce has only started in recent years and there is handful of direct literature in the U.S. and China.

\subsection{Trends in E-Commerce Research}

With its increasing sales and share of market, e-commerce research transforms into how to innovate new products and services to draw participants and create new operation modes. However, the key point is to examine participants' attitudes and preferences regarding the use of electronic commerce ${ }^{[84]}$ and use data analysis technologies to examine them ${ }^{[84]}$. For instance, academic research often focuses on the capability of recommender systems that adopt data analysis approaches, such as a learning-based approach, to help judge users by their long-term preference profiles ${ }^{[85]}$. Another aspect of this research is investigating patterns in e-commerce activities and their impact on the economy; this type of research also utilizes statistical analysis approaches ${ }^{[86]}$. As a consequence, it is believed that the research trends of the e-commerce domain are linked to other disciplines, such as computer science, engineering, information science,

\footnotetext{
${ }^{2}$ Data come from the Statista website, https://www.statista.com/statistics/379046/worldwide-retail-ecommerce-sales/.

${ }^{3}$ Data come from the Statista website, https://www.statista.com/statistics/534114/e-commerce-share-ofretail-sales-in-APAC/.

${ }^{4}$ Data come from the Statista website, https://www.statista.com/statistics/379112/e-commerce-share-ofretail-sales-in-US/.

${ }^{5}$ Data come from the Statista website, https://www.statista.com/statistics/379087/e-commerce-share-ofretail-sales-in-China/.
} 
telecommunications, psychology, social sciences, and mathematics, which are ${ }^{[87]}$ involved with the most cutting-edge scientific and technological methods. For the U.S. and China, Tsai ${ }^{[87]}$ explores e-commerce research trends through an analysis of the SSCI database in the past and forecasts that both countries will produce more e-commerce literature in the future.

\subsection{Online Consumer Behavior}

As a focal research trend of e-commerce activities and participants' preferences, online consumer behavior has attached importance in the U.S. and China, not only in research but also in practice. However, studies that help to understand consumers' views and their behavior towards applications of BDA are lacking ${ }^{[88]}$. Articles on big data initiatives in statistical and artificial intelligence are popular among relative periodicals ${ }^{[89]}$. The theoretical framework of online consumer behavior usually integrates information systems (technology acceptance model), marketing (consumer behavior), and psychology (flow and environmental psychology) $)^{[90]}$ and then statistically analyzes the large amount of data. In particular, these dynamic irregular unexpected behaviors require key determinants determined through BDA, such as online impulse buying regardless of website quality ${ }^{[91]}$, helping merchants adapt their website content in real time to capture the current preferences of online customers, and using data mining and other clickstream analysis techniques ${ }^{[92]}$. With the help of social media, e-commerce presents new social characteristics and interactive behaviors ${ }^{[33]}$ that can integrate qualitative interaction content data and consumer transactions data to assemble a unique data set using content analysis methods ${ }^{[94]}$. In addition, Ghose ${ }^{[95]}$ study the effects of search engine rankings on consumer behavior using archival data analysis that unravels the economic impact of ranking (including search engine ranking, product rating, and personalized ranking) and its interaction with social media on product search engines.

In short, e-commerce issues concerning transaction behavior will increasingly consider data analysis techniques and tools to process and learn data and then obtain valuable information to support decision-making. Considering the retrieval consequence presented in Table A7, the U.S. and China are mainly consistent in academic research, where the search subject term 'Online Consumer Behavior' classified by the field of 'title' occurs several times in the WoS (Core Collection) and CNKI (All), whereas they differ in the search subject terms 'Online Consumer Behavior' and 'Big Data' simultaneously classified by the field of 'topic'. Barely any papers are found in the CNKI database. Obviously, China's academic discussion of online consumer behavior has not started to adopt BDA, which is inappropriate considering its great achievements in e-commerce industrialization, particularly in retail web sales, which totaled 7.18 trillion yuan (\$1.149 trillion) in $2017^{6}$. One possible reason for the lack of adoption of BDA is that the contribution of academic research on e-commerce in China is limited to industry or applications, and this point will be examined and verified below.

\subsection{Internet of Things in E-Commerce}

The Internet of Things (IoT) is gaining increasing popularity in every field, including ecommerce $^{[96]}$, as shown by Google results for the 'Internet of Things in e-commerce' on July-

\footnotetext{
${ }^{6}$ Data come from the Digital Commerce 360 website, https://www.digitalcommerce360.com/2018/02/08/onlineretail-sales-china-soar-past-1-trillion-2017/.
} 
2-2018, which included approximately 180 million entries; Baidu was included in at 3.9 million entries. Accordingly, the academic research trends in both the U.S. and China present rapid growth, as shown in Table A8, especially that of China, which shows a more significant increase in this field than the U.S. As a vital technique of connecting interorganizational operations and processes, RFID is used to build the IoT such that a network would allow companies to track goods ${ }^{[97-99]}$ and close some of the information gaps in e-commerce ${ }^{[100]}$. Moreover, Samue ${ }^{[101]}$ proposes a 'Living Laboratory' strategy approach that properly fills the gap identified in the current RFID literature. $\mathrm{Hsu}^{[102]}$ considers the newest information technology that will change the e-commerce module and then provides a framework for creating e-commerce models for IoT applications. The growth of the number of intelligent devices will create a network rich with information and allow data to be seamlessly transferred to the Internet via the $\operatorname{IoT}^{[103]}$, which obviously presents unprecedented business opportunities and profoundly impacts the existing concept of e-commerce. For example, a system based on beacon technology that can detect the location and experience information of customers inside shops will send data to a server for processing to provide the customers with better service ${ }^{[104]}$; in addition, for data applied to e-commerce, the innovative application of the Internet of Things in e-commerce is faster and wider $^{[105-107]}$, even in rural China ${ }^{[08]}$. Undoubtedly, future technologies, such as the Internet of Things, big data analytics, and cloud computing, will be widely adopted to enhance e-commerce logistics at the system level, operational level, and decision-making level and may function in real time and be intelligent in the next decade ${ }^{[109]}$.

\subsection{Mobile Technology in E-Commerce}

Mobile devices and social media have led to a profound revolution of modern society, obliging many companies to reorient their sales systems toward more successful commercial formats (mobile commerce and social commerce ${ }^{[110]}$. The literature on mobile commerce was started early and can placed into five distinct categories: mobile commerce theory and research, wireless network infrastructure, mobile middleware, wireless user infrastructure, and mobile commerce applications and cases ${ }^{[111]}$. On account of the differences of age, trust, social influence, etc., which affect consumer intention and behavior in mobile commerce ${ }^{[112]}$, the U.S. has focused less than China on mobile technology in e-commerce in practice but has more positive discussion than China in academic research, as shown in Table A8. China's booming mobile commerce benefits from its mobile payment technology, which can be defined as any payment transaction involving the purchase of goods or services completed with wireless devices ${ }^{[113]}$. Nevertheless, e-commerce, especially mobile commerce, is being taken not only as a technical difficulty but also as a great opportunity in areas such as those that exist in the least developed countries ${ }^{[14]}$. In addition, SMEs from the least developed countries have indicated that it is not necessary to invest in transactive web-based e-commerce because mobile technology, especially mobile payment services, is already fulfilling their transactional needs ${ }^{[114]}$. For mobile technology innovation in e-commerce, Spott is an innovative second screen mobile multimedia application that offers viewers relevant information on goods they see and like on their television screens ${ }^{[15]}$. Other applications of mobile devices and social media networks, such as Facebook and WeChat, have revolutionized the e-commerce adoption process in SMEs ${ }^{[16]}$. The prevalent consumption channel with portable devices has led to an emerging pattern of online-to-offline (O2O) 
purchasing behavior using quick response codes (QR codes) ${ }^{[117]}$.

In short, the role of mobile devices is growing in importance among society, with increasingly more mobile applications compared with traditional devices (laptop, desktop computer) being used to communicate with the Internet every year ${ }^{[18]}$. Of course, there are also many trends of mobile technology in e-commerce that should be discussed ${ }^{[12]}$. Although the new mobile payment service can provide users and stores with various benefits, it also introduces new security concerns and vulnerabilities ${ }^{[119]}$, and a lack of in-depth user and resources information has become the main bottleneck restricting the predictive analytics of recommendation systems in mobile commerce ${ }^{[120]}$.

\subsection{Cloud Computing in E-Commerce}

E-commerce contributions to developing countries' economies may face a challenge due to the lack of telecommunications infrastructure; fortunately, cloud computing offers a solution to most of these challenges, providing access to a low-cost, reliable and flexible internetbased infrastructure ${ }^{[121]}$. The e-commerce applications of cloud computing enable businesses to rapidly respond to market changes, and the increasing usage of cloud computing and mobile devices is reshaping the regular methods of computing and storing information, which improve e-commerce businesses' technical architecture ${ }^{[122]}$. The combination of cloud computing and ecommerce can reliably and validly predict the benefits of e-commerce ${ }^{[123,124]}$ and is extensively applied in the logistics industry ${ }^{[125-127]}$ and financial services ${ }^{[128]}$. Together with the explosive growth of mobile applications and the emergence cloud computing, mobile cloud computing in e-commerce ${ }^{[129]}$ has been introduced to mobile commerce, mobile learning, mobile healthcare, mobile gaming, etc. ${ }^{[130]}$. In addition, the architectures and models for adoption of cloud computing in e-commerce ${ }^{[131-137]}$ are both discussed in U.S. and Chinese literature databases, but China focuses more on issues in this domain, as shown in Table A8.

\subsection{Artificial Intelligence in E-Commerce}

The research domain of artificial intelligence in e-commerce tends to study microproblems of e-commerce, of which users' attitudes and preferences, transaction characteristics and behaviors are studied and solved using many techniques. In 2007, a knowledge-based intelligent e-commerce system ${ }^{[138]}$ was presented for decision-making and provided feasible solutions or actions based on the results of rule-based reasoning via the Internet. Then, $\mathrm{Hu}^{[139]}$ solved the key technical problem of real-time intelligent order processing in $\mathrm{B} 2 \mathrm{C}$ e-commerce. In recent years, recommender systems have been developed, which typically produce a list of recommendations to precisely predict users' preference for items ${ }^{[140]}$, as well as online consumer reviews ${ }^{[141]}$, and are good for helping customers learn about the strengths and weaknesses of different products and to find those that best suit their needs ${ }^{[142]}$; moreover these systems can discover the underlying sentiments toward different aspects in review texts and associate the rating scores with these sentiments ${ }^{[109,143]}$. A number of research methodologies and intelligence technologies have been used to investigate e-commerce issues, for example, a computational intelligence system architecture integrated the techniques of singular value decomposition and dimensionality reduction, fuzzy c-means and the adaptive neuro-fuzzy inference system for rating prediction, as described by Georgina ${ }^{[144]}$; biometric methods for predicting dynamic behaviors ${ }^{[45]}$; and 
applications in the context of time series forecasting using $k \mathrm{NN}$ regression ${ }^{[146]}$. Therefore, understanding consumer perceptions and influential factors through online customer reviews ${ }^{[147]}$ to predict and analyze in practical industries ${ }^{[48]}$ are prevalent in research. In 2018, more pure and mature artificial intelligence technologies were using e-commerce while producing large volumes of data every day in the era of big data. $\mathrm{Ali}^{[149]}$ proposed a robust semisupervised growing self-organizing map for online classification with partial labeled data and extracted knowledge, and Rafailidis ${ }^{[150]}$ proposed a multilatent transition model to identify the correlation between users' recent and past preferences to generate accurate recommendations. With the increasing default in e-commerce, Leonardo ${ }^{[151]}$ implemented risk management in an artificial intelligence system that is in the process of genetic programming. Likewise, Thambo ${ }^{[152]}$ built automated designed genetic programming classifiers for data and then contrasted them with manually designed GP classifiers. Thus, artificial intelligence in e-commerce is a new and burgeoning research field in both the U.S. and China, as shown in Table A8.

\section{Prospects}

Regardless of whether the U.S. or China is considered, the theoretical research work is deeply impressing and has propelled practical application of BDA in e-commerce. And the next research work is going to find out the theoretical achievements how to promote the actual economic activity on BDA in e-commerce, and the different of this two between U.S. and China.

\section{References}

[1] Chen H, Chiang R H L, Storey V C. Business intelligence and analytics: From big data to big impact. MIS Quarterly, 2012, 36(4): 1165-1188.

[2] Sun Z H, Sun L Z, Strang K. Big data analytics services for enhancing business intelligence. Journal of Computer Information Systems, 2018, 58(2): 162-169.

[3] Davenport T H. Competing on analytics. Harvard Business Review, 2006, 84(1): 98-107.

[4] Andreas S, Josef S. Enhanced business intelligence-supporting business processes with real-time business analytics. The 16th International Workshop on Database and Expert Systems Applications (DEXA'05), Copenhagen, Denmark, 2005.

[5] Niu L, Lu J, Zhang G Q. Improved business intelligence analytics on manager's experience. The 2008 IEEE Congress on Evolutionary Computation, Hong Kong, China, 2008.

[6] Bhatnagar A. Web analytics for business intelligence beyond hits and sessions. ONLINE, 2009, 33(6): $32-35$.

[7] Laursen G H N, Thorlund J. Business analytics for managers taking business intelligence beyond reporting. John Wiley \& Sons, New Jersey, 2010.

[8] Green A. Engineering business reasoning, analytics and intelligence network (E-BRAIN): A new approach to intangible asset valuation based on Einstein's perspective. Identifying, Measuring, and Valuing Knowledge-Based Intangible Assets: New Perspectives. Belen V A (ed). IGI Global, New York, 2011: 232-253.

[9] Basole R C, Hu M, Patel P, et al. Visual analytics for converging-business-ecosystem intelligence. IEEE Computer Graphics and Applications, 2012, 32(1): 92-96.

[10] Shan C, Porikli F, Xiang T, et al. Video analytics for business intelligence. Studies in Computational Intelligence, 2012, 409: 1-373.

[11] Qiu R G. Business-oriented enterprise integration for organizational agility. IGI Global, Hersey, PA, USA, 2013.

[12] Ruhi U. Social media analytics as a business intelligence practice: Current landscape \& future prospects. Journal of Internet Social Networking \& Virtual Communities, 2014, 2014: 1-12.

[13] Elias M. Aufaure M A, Bezerianos A. Storytelling in visual analytics tools for business intelligence. Human- 
Computer Interaction - INTERACT 2013. Kotzé P, Marsden G, Lindgaard G, Wesson J, Winckler M (eds). Lecture Notes in Computer Science, vol 8119. Springer, Berlin, Heidelberg, 2013: 280-297.

[14] Paul Z, Chris E. Understanding big Data: Analytics for enterprise class Hadoop and streaming data (1st ed.). McGraw-Hill Osborne Media, New York, 2011.

[15] Escobedo G, Jacome N, Arroyo-Figueroa G. Business intelligence and data analytics (BI\&DA) to support the operation of smart grid. The International Conference on Internet of Things and Big Data (IoTBD 2016), Rome, Italy, 2016.

[16] Danyel F, Steven D, Mary C. Business intelligence analytics. IEEE Computer Graphics and Applications, 2014, 34(5): 22-24.

[17] Matthias D, Frank E S. Frontiers in data science. CRC Press Taylor \& Francis Group, Boca Raton, FL, 2017.

[18] Kumar U D. Foreword. Journal of Information and Optimization Sciences, 2016, 37(5): iii.

[19] Ram J, Zhang C Y, Koronios A. The implications of big data analytics on business intelligence: A qualitative study in China. Procedia Computer Science, 2016, 87: 221-226.

[20] Lautenbach P, Johnston K, Adeniran-Ogundipe T. Factors influencing business intelligence and analytics usage extent in South African organisations. South African Journal of Business Management, 2017, 48(3): 23-33.

[21] Isik O, Jones M C, Sidorova A. Business intelligence (BI) success and the role of BI capabilities. Intelligent Systems in Accounting. Finance and Management, 2011, 18(4): 161-176.

[22] Wixom B, Watson H. The BI-based organization. International Journal of Business Intelligence Research, 2010, 1(1): 13-28.

[23] Foshay N, Yeoh W, Boo Y L, et al. A comprehensive diagnostic framework for evaluating business intelligence and analytics effectiveness. Australasian Journal of Information Systems, 2015, 19: S37-S54.

[24] Yahaya J H, Deraman A, Abai N H Z, et al. Business intelligence and big data analytics for organizational performance management in public sector: The conceptual framework. Advanced Science Letters, 2016, 22(8): 1919-1923.

[25] Ali O, Crvenkovski P, Johnson H. Using a business intelligence data analytics solution in healthcare. 7th IEEE Annual Information Technology, Electronics and Mobile Communication Conference (IEEE IEMCON), Vancouver, BC, Canada, 2016.

[26] Mishra B K, Hazra D, Tarannum K, et al. Business intelligence using data mining techniques and business analytics. The 5th International Conference System Modeling and Advancement in Research Trends (SMART), Moradabad, India, 2016.

[27] Jayaram A, Singal S. An enterprise resource management model for business intelligence, data mining and predictive analytics. The 7th International Conference on Cloud Computing, Data Science and Engineering (Confluence), Noida, India, 2017.

[28] Hakeem A, et al. Video analytics for business intelligence. Video Analytics for Business Intelligence. Shan C, Porikli F, Xiang T, Gong S (eds). Studies in Computational Intelligence, vol 409. Springer, Berlin, Heidelberg, 2012: 309-354.

[29] Anna Q, Jonathan M, Henning B. Fusing storage and computing for the domain of business intelligence and analytics - Research opportunities. The 48th Hawaii International Conference on System Sciences, Kauai, HI, USA, 2004.

[30] Olivera M. From analytics-as-a-service to analytics-as-a-consumer-service: Exploring a new direction in business intelligence and analytics research. The 2015 48th Hawaii International Conference on System Sciences, HI, USA, 2014.

[31] Christopher J Z, Henricus T W J W, Ravi V. Building a social newsroom: Visual analytics for social business intelligence. The IEEE 19th International Enterprise Distributed Object Computing Workshop, Adelaide, SA, Australia, 2015.

[32] Bala M B, Shivika P. Challenges and benefits of deploying big data analytics in the cloud for business intelligence. Procedia Computer Science, 2017, 112: 1112-1122.

[33] Omar E G, Prem T. Opportunities for business intelligence and big data analytics in evidence based medicine. The 2014 47th Hawaii International Conference on System Science, HI, USA, 2014.

[34] Neill C, Roushan P, Kechedzhi K, et al., A blueprint for demonstrating quantum supremacy with superconducting qubits. Science, 2018, 360(6385): 195-199. 
[35] Ram J, Zhang C Y, Andy K. The implications of big data analytics on business intelligence: A qualitative study in China. Procedia Computer Science, 2016, 87: 221-226.

[36] Marilex R L. Business intelligence and analytics in small and medium-sized enterprises: A systematic literature review. Procedia Computer Science, 2017, 121: 194-205.

[37] Dinesh B. Adapting agile practices for data warehousing, business intelligence, and analytics. Journal of Database Management, 2017, 28(4): 1-23.

[38] Shao C X, Pan X W, Qi G N, et al. Research and practice on mode of data analysis agent (DAA) in business intelligence. Manufacturing Automation, 2004, 26(8): 6-9 (in Chinese).

[39] Kong L F, Liu C M, Zhu K. Application of business intelligence in new business ecosystem. Journal of Modern Information, 2005, 25(2): 189-191 (in Chinese).

[40] Hong S, Liu J C, Yan X G. Build BI analysis \& report publish system within NET framework. Computer Applications and Software, 2007, 24(3): 96-98 (in Chinese).

[41] Ma M, Zhao Y C. A framework of real-time business intelligent and its technical analysis. Computer Applications and Software, 2009, 26(10): 130-132 (in Chinese).

[42] Yu Z H, Ji X. A comparative study on the business intelligence search engines and the traditional search engines. Shanghai Management Science, 2010, 32(5): 87-92 (in Chinese).

[43] Gao Q Y, She B, Guo W, et al. Online multisource data integration and interactive geovisual analytics in spatial business intelligence. Journal of Geomatics, 2015, 40(1): 61-64 (in Chinese).

[44] Zong P, Wang W J. An analysis of mainstream business intelligence software. Computer Engineering \& Science, 2006, 28(12): 4-7 (in Chinese).

[45] Chen H Y. Design and implementation in insurance data analysing and decision-making based on business intelligence. Computer Systems and Applications, 2010, 19(11): 139-142 (in Chinese).

[46] Song X, Guo J, Yin S Y, et al. Application of business intelligence in historical data statistical analysis of power dispatch and control system. Automation of Electric Power Systems, 2015, 39(12): 93-96 (in Chinese).

[47] Pareek D. 5 reasons why the big data market is exploding. Datafloq, March. https://datafloq.com/read/5Reasons-Big-Data-Market-is-Exploding/1948 (accessed 26 April 2018).

[48] Brynjolfsson E, Hitt L M, Heekyung K. Strength in numbers: How does data-driven decision-making affect firm performance? SSRN, April 2011. http://dx.doi.org/10.2139/ssrn.1819486.

[49] Goes P B. Editor's comments: Big data and IS research. MIS Quarterly, 2014, 38(3): 3-8.

[50] Naveen K, Vasudha B. Big Data Analytics. 4th International Conference on Big Data Analytics (BDA 2015). Lecture Notes in Computer Science, 9498, Springer: Cham, Switzerland, 2015: 3-266.

[51] Raj B. Design of algorithms for big data analytics. Big Data Analytics (BDA 2015). Kumar N, Bhatnagar V (eds). Lecture Notes in Computer Science, Springer: Cham, 2015: 101-107.

[52] Masashi T. Mobility big data analysis and visualization (Invited Talk). The 4th International Conference on Big Data Analytics (BDA 2015), Lecture Notes in Computer Science, Hyderabad, India, 2015.

[53] Kiran R U, Kitsuregawa M. Finding periodic patterns in big data. Big Data Analytics (BDA 2015). Kumar N, Bhatnagar V (eds). Lecture Notes in Computer Science, Springer: Cham, 2015: 121-133.

[54] Surbhi B, Subrat K D. VDMR-DBSCAN: Varied Density MapReduce DBSCAN. Big Data Analytics (BDA 2015). Kumar N, Bhatnagar V (eds). Lecture Notes in Computer Science, Springer: Cham, 2015: $134-150$.

[55] Goel V, Chaudhary B D. Concept discovery from un-constrained distributed context. Big Data Analytics (BDA 2015). Kumar N, Bhatnagar V (eds). Lecture Notes in Computer Science, Springer: Cham, 2015: 151-164.

[56] Astha S, Kunal G, Ashish S. Khanan: Performance comparison and programming $\alpha$-Miner algorithm in column-oriented and relational database query languages. Big Data Analytics, Kumar N, Bhatnagar V (eds). Lecture Notes in Computer Science, Springer: Cham, Switzerland, 2015: 165-180.

[57] Arpita N, Deepti G. A new proposed feature subset selection algorithm based on maximization of gain ratio. Big Data Analytics. Kumar N, Bhatnagar V (eds). Lecture Notes in Computer Science, Springer: Cham, Switzerland, 2015: 181-197.

[58] Ylijoki O, Porras J. Perspectives to definition of big data: A mapping study and discussion. Journal of Innovation Management, 2016, 4(1): 69-91.

[59] Laney D. 3D data management: Controlling data volume, velocity, and variety. Technical report. META 
Group research note, 2001, 6(70): 1.

[60] Hashem I A T, Yaqoob I, Aunar N B, et al. The rise of "big data" on cloud computing: Review and open research issues. Information Systems, 2015, 47: 98-115.

[61] Jain P, Gyanchandani M, Khare N. Big data privacy: A technological perspective and review. Journal of Big Data, 2016, 3(1): 3-25.

[62] Duygu S T, Ramazan T, Seref S. Big data analytics for network anomaly detection from netflow data. The 2017 International Conference on Computer Science and Engineering (UBMK), Antalya, Turkey, 2017.

[63] Ularu E G, Puican F C, Apostu A, et al. Perspectives on big data and big data analytics. Database Systems Journal, 2012, 3(4): 3-14.

[64] Miele S, Shockley R. Analytics: The real-world use of big data. IBM Global Business Services, 2013, 12: $1-20$.

[65] Gantz J, Reinsel D. Extracting value from chaos. Framingham: IDC iView, June. https://www.emcgrand prix.com/collateral/analyst-reports/idc-extracting-value-from-chaos-ar.pdf.

[66] Fan W, Bifet A. Mining big data: Current status, and forecast to the future. ACM SIGKDD Explorations Newsletter, 2012, 14(2): 1-5.

[67] Dijcks J P. Oracle: Big data for the enterprise. Redwood shores: Oracle corporation, June. http://www.oracle.com/us/products/database/big-data-for-enterprise-519135.pdf.

[68] Aditya B P, Manashvi B, Ushma N. Addressing big data problem using Hadoop and Map Reduce. The 3rd Nirma-University International Conference on Engineering (NUiCONE), Ahmedabad, India, 2012.

[69] Shankar G M, Siddarth R. Big data analysis using Apache Hadoop. The 2014 International Conference on IT Convergence and Security (ICITCS), Beijing, China, 2014.

[70] Song J, Guo C P, Wang Z, et al. HaoLap: A Hadoop based OLAP system for big data. The Journal of Systems and Software, 2015, 102: 167-181.

[71] Qin P, Dai B, Huang B X, et al. Bandwidth-aware scheduling with SDN in Hadoop: A new trend for big data. IEEE Systems Journal, 2017, 11(4): 2337-2344.

[72] Rathore M M, Son H, Ahmad A, et al. Real-time big data stream processing using GPU with Spark over Hadoop ecosystem. International Journal of Parallel Programming, 2018, 46(3): 630-646.

[73] Rani S, Ahmed S H, Talwar R, et al. Can sensors collect big data? An energy-efficient big data gathering algorithm for a WSN. IEEE Transactions on Industrial Informatics, 2017, 13(4): 1961-1968.

[74] Alexander E, Dmitry K, Mais F. Modern methods to collect, store, and process big data in large-scale systems. The 5th International Conference on Control, Instrumentation, and Automation (ICCIA), Shiraz, Iran, 2017.

[75] Gueta T, Carmel Y. Quantifying the value of user-level data cleaning for big data: A case study using mammal distribution models. Ecological Informatics, 2016, 34: 139-145.

[76] Verma S. Big data and advance analytics: Architecture, techniques, applications, and challenges. International Journal of Business Analytics, 2017, 4(4): 21-47.

[77] Adrian G, Martina K L, Terrence J O N, et al. Big data techniques in auditing research and practice: Current trends and future opportunities. Journal of Accounting Literature, 2018, 40: 102-115.

[78] Albeshri A, Thayananthan V. Analytical techniques for decision making on information security for big data breaches. International Journal of Information Technology \& Decision Making, 2018, 17(2): 527-545.

[79] Shan S. Machine learning models and algorithms for big data classification. Springerr Science+Business Media, New York, 2016.

[80] Zhang Q C, Yang L T, Chen Z K, et al. A survey on deep learning for big data. Information Fusion, 2018, 42: $146-157$.

[81] Henry F N, Ying W T, Mohammed A A, et al. Deep learning algorithms for human activity recognition using mobile and wearable sensor networks: State of the art and research challenges. Expert Systems With Applications, 2018, 105: 233-262.

[82] Kalyan V, Ignacio A, Vamsi K, et al. AI2: Training a big data machine to defend. The 2016 IEEE 2nd International Conference on Big Data Security on Cloud (BigDataSecurity), IEEE International Conference on High Performance and Smart Computing (HPSC), and IEEE International Conference on Intelligent Data and Security (IDS), New York, USA, 2016.

[83] Shahriar A, Samuel F W. Big data analytics in e-commerce: A systematic review and agenda for future research. Electron Markets, 2016, 26(2): 173-194. 
[84] Vergil V, Simona N V, Daniela Ş, et al. An analysis of the Romanian e-commerce trade trends in European perspective. Economic Computation and Economic Cybernetics Studies and Research, 2016, 50(1): 235252.

[85] Dietmar J, Malte L, Lukas L. Session-based item recommendation in e-commerce: On short-term intents, reminders, trends and discounts. User Modeling and User-Adapted Interaction, 2017, 27(3-5): 351-392.

[86] Martin F, Eva H. E-commerce trends and impacts across Europe. International Journal of Production Economics, 2015, 170(Part A): 357-369.

[87] Tsai H H. The research trends forecasted by bibliometric methodology: A case study in e-commerce from 1996 to July 2015. Scientometrics, 2015, 105(2): 1079-1089.

[88] Le T M, Liaw S Y. Effects of pros and cons of applying big data analytics to consumers' responses in an e-commerce context. Sustainability, 2017, 9(5): 798(1-19).

[89] Fan S K, Xiao J H, Xie K, et al. Introduction to the special issue of ECR on e-business innovation with big data. Electronic Commerce Research, 2017, 17(1): 1.

[90] Marios K. Applying the technology acceptance model and flow theory to online consumer behavior. Information Systems Research, 2002, 13(2): 205-223.

[91] Parboteeah D V, Valacich J S, Wells J D. The influence of website characteristics on a consumer's urge to buy impulsively. Information Systems Research, 2009, 20(1): 60-78.

[92] Shuk Y H, David B, Kar Y T. Timing of adaptive web personalization and its effects on online consumer behavior. Information Systems Research, 2011, 22(3): 660-679.

[93] Gerald H, Valerie T. Consumer decision making in online shopping environments: The effects of interactive decision aids. Marketing Science, 2000, 19(1): 4-21.

[94] Goh K Y, Heng C S, Lin Z J. Social media brand community and consumer behavior: Quantifying the relative impact of user- and marketer-generated content. Information Systems Research, 2013, 24(1): 88-107.

[95] Ghose A, Ipeirotis P G, Li B B. Examining the impact of ranking on consumer behavior and search engine revenue. Management Science, 2014, 60(7): 1632-1654.

[96] Srisakdi C, Pornpisud M. Internet of things in e-Business. The 10th International Conference on e-Business (iNCEB2015), Bangkok, Thailand, 2015.

[97] Violino B. Leveraging the internet of things. RFID Journal, 2005: 18-27.

[98] Ngai E W T, Moon K K L, Riggins F J, et al. RFID research: An academic literature review (1995-2005) and future research directions. International Journal of Production Economics, 2008, 112(2): 510-520.

[99] Sergei E, Benjamin F, Oliver G, et al. RFID and the internet of things: Technology, applications, and security challenges. Foundations and Trends in Technology. Information and Operations Management, 2010, 4(2): 105-185.

[100] Rebecca A. RFID technologies: Supply-chain applications and implementation issues. Information Systems Management, 2005, 22(1): 51-65.

[101] Samuel F W. Achieving supply chain integration using RFID technology: The case of emerging intelligent B-to-B e-commerce processes in a living laboratory. Business Process Management Journal, 2012, 18(1): 58-81.

[102] Hsu L F. E-commerce model based on the internet of things. Advanced Science Letters, 2016, 22(10): 3089-3091.

[103] Sachchidanand S, Nirmala S. Internet of things (IoT): Security challenges, business opportunities \& reference architecture for e-commerce. The 2015 International Conference on Green Computing and Internet of Things (ICGCIoT), Noida, India, 2015.

[104] Prasad S, Shivani M, Sachin C, et al. Innovative ideas to improve shopping mall experience over e-commerce websites using beacon technology and data mining algorithms. The 2017 International Conference on Circuit, Power and Computing Technologies (ICCPCT), Kollam, India, 2017.

[105] Dani G. Protocol for e-commerce data harvesting. The 2015 International Conference on Technology, Informatics, Management, Engineering \& Environment (TIME-E), Samosir, Indonesia, 2015.

[106] Peiman D, Uwe C, Esther D. An investigation of behavioural and structural characteristics of CEP service providers and freight demand considering e-commerce in Germany. Transportation Research Procedia, 2016, 14: 2795-2804.

[107] Ruan J H, Shi Y. Monitoring and assessing fruit freshness in IOT-based e-commerce delivery using scenario 
analysis and interval number approaches. Information Sciences, 2016, 373: 557-570.

[108] Huang Z H. A study of e-commerce transaction risk assessment model in mobile internet. Journal of Electronic Commerce in Organizations, 2017, 15(4): 1-10.

[109] Yu D J, Mu Y L, Jin Y K. Rating prediction using review texts with underlying sentiments. Information Processing Letters, 2017, 117: 10-18.

[110] Francisco M, María P F, María D P G. Dealing with seasonality by narrowing the training set in time series forecasting with $k$ NN. Expert Systems with Applications, 2018, 103: 38-48.

[111] Ngai E W T, Gunasekaran A. A review for mobile commerce research and applications. Decision Support Systems, 2007, 43(1): 3-15.

[112] Alain Y L C, Felix T S C, Keng-Boon O. Predicting consumer decisions to adopt mobile commerce: Cross country empirical examination between China and Malaysia. Decision Support Systems, 2012, 53(1): 3443.

[113] Gu R J, Yao J, Wang J C. Research on mobile payment technology and business models in China under e-commerce environment. Future Generation Information Technology. Kim T, Lee Y, Kang B H, Ślęzak D (eds). FGIT 2010, Lecture Notes in Computer Science, Springer: Berlin, Heidelberg, 2010: 334-343.

[114] Salah K, Irwin B. A structuration analysis of small and medium enterprise (SME) adoption of e-commerce: The case of Tanzania. Telematics and Informatics, 2017, 34(4): 118-132.

[115] Florian V, Karel V, Dimitri S, et al. Spott: On-the-spot e-commerce for television using deep learningbased video analysis techniques. ACM Transactions on Multimedia Computing, Communications, and Applications, 2017, 13(3s): 1-17.

[116] Alice P S, Chris P. E-commerce and entrepreneurship in SMEs: Case of myBot. Journal of Small Business and Enterprise Development, 2018, 25(3): 501-520.

[117] Lin S Y, Chen S C, Chuang S H. Perceived innovation and quick response codes in an online-to-offline e-commerce service model. International Journal of E-Adoption, 2017, 9(2): 1-16.

[118] Witold C, Tomasz P. The use of mobile technologies in e-commerce. The Proceedings of ICERI2017 Conference, Seville, Spain, 2017.

[119] Ashay S J, Joon S P. Towards trusted mobile payment services: A security analysis on Apple Pay. International Journal of Internet of Things and Cyber-Assurance, 2018, 1(1): 76-90.

[120] Guo Y, Yin C X, Li M H, et al. Mobile e-Commerce recommendation system based on multi-source information fusion for sustainable e-Business. Sustainability, 2018, 10(1): 147.

[121] Ghada R E S. A cloud computing-based model of e-commerce adoption for developing countries. Journal of Electronic Commerce in Organizations, 2017, 15(3): 64-82.

[122] Huo Y Y. Research on e-commerce architecture based on cloud computing. The Asia-Pacific Management and Engineering Conference (APME 2014), Shanghai, China, 2014.

[123] Fu Z H. Research on the prediction of the e-commerce profit based on the improved parallel PSO-LSSVM algorithm in cloud computing environment. International Journal of Grid and Distributed Computing, 2016, 9(6): 369-380.

[124] Han G. Research on the e-commerce sales forecast based on the improved parallel chaos algorithm in the cloud computing. International Journal of Grid and Distributed Computing, 2016, 9(6): 359-368.

[125] Shen Y Y, Qian Y. A study of new e-commerce logistics mode based on cloud computing technology. Advanced Materials Research, 2014, 1049-1050: 1848-1852.

[126] Li Q. Research on the information management problems in the linkage process of manufacturing and logistics industry. Proceedings of the 6th International Asia Conference on Industrial Engineering and Management Innovation, Qi E (eds). Atlantis Press: Paris, 2015: 943-950.

[127] Liang D, Wu S, Sun G Z. Value chain optimization of B2C e-commerce based on cloud computing and ITM. Proceedings of the 6th International Asia Conference on Industrial Engineering and Management Innovation. Atlantis Press: Paris, 2015: 951-962.

[128] Yu X F, Zhao Y M, Wang Y. The innovation of e-commerce financial service product based on cloud computing - Taking Alibaba finance as an example. The 2013 10th International Conference on Service Systems and Service Management, Hong Kong, China, 2013.

[129] Pop F, Dobre C, Mocanu B C, et al. Trust models for efficient communication in mobile cloud computing and their applications to e-commerce. Enterprise Information Systems, 2016, 10(9): 982-1000.

[130] Hoang T D, Chonho L, Dusit N, et al. A survey of mobile cloud computing: Architecture, applications, 
and approaches. Wireless Communications and Mobile Computing, 2013, 13: 1587-1611.

[131] Wasin T. E-commerce transaction security model based on cloud computing. The 2012 IEEE 2nd International Conference on Cloud Computing and Intelligence Systems, Hangzhou, China, 2012.

[132] Yu J, Ni J. Development strategies for SME e-commerce based on cloud computing. The 2013 Seventh International Conference on Internet Computing for Engineering and Science, Shanghai, China, 2013.

[133] Rao T K R K, Khan S A, Begum Z, et al. Mining the e-commerce cloud: A survey on emerging relationship between web mining, e-commerce and cloud computing. The 2013 IEEE International Conference on Computational Intelligence and Computing Research, Enathi, India, 2013.

[134] Nafi K W, Kar T S, Hossain M A, et al. A new trusted and secured e-commerce architecture for cloud computing. The 2013 2nd International Conference on Informatics, Electronics and Vision, Dhaka, Bangladesh, 2013.

[135] Wang B, Tang J. The analysis of application of cloud computing in e-commerce. The 2016 International Conference on Information System and Artificial Intelligence, Hong Kong, China, 2016.

[136] Kanu G, Manu G. Cloud computing based e-commerce model. The 2016 IEEE International Conference On Recent Trends In Electronics Information Communication Technology, Bangalore, India, 2016.

[137] Osama S, Mohsen N. Decision making on adoption of cloud computing in e-commerce using fuzzy TOPSIS. The 2017 IEEE International Conference on Fuzzy Systems, Naples, Italy, 2017.

[138] Wen W. A knowledge-based intelligent electronic commerce system for selling agricultural products. Computers and Electronics in Agriculture, 2007, 57(1): 33-46.

[139] Hu X P, Wang X Y, Sun L J, et al. A real-time intelligent system for order processing in B2C e-commerce. International Journal of Innovative Computing, Information and Control, 2009, 5(11A): 3691-3706.

[140] Yu Y, Wang X, Zhong R Y, et al. E-commerce logistics in supply chain management: Implementations and future perspective in furniture industry. Industrial Management \& Data Systems, 2017, 117(10): 2263-2286.

[141] Rully A H, Erma S, Rani O. Evaluation of e-commerce product reviews based on structural, metadata, and readability characteristics. Procedia Computer Science, 2017, 124: 280-286.

[142] Mohammad S, Dan J K. Predicting the performance of online consumer reviews: A sentiment mining approach to big data analytics. Decision Support Systems, 2016, 81: 30-40.

[143] Liu Y, Bi J W, Fan Z P. Ranking products through online reviews: A method based on sentiment analysis technique and intuitionistic fuzzy set theory. Information Fusion, 2017, 36: 149-161.

[144] Georgina C, Giovanni A. A computational intelligence approach to efficiently predicting review ratings in e-commerce. Applied Soft Computing, 2016, 44: 153-162.

[145] Marcin Z, Krystian L, Krzysztof C. Prediction of values of the dynamic signature features. Expert Systems with Applications, 2018, 104: 86-96.

[146] Francisco M, María P F, María D P G. Dealing with seasonality by narrowing the training set in time series forecasting with $k$ NN. Expert Systems with Applications, 2018, 103: 38-48.

[147] Xu X, Wang X Q, Li Y B, et al. Business intelligence in online customer textual reviews: Understanding consumer perceptions and influential factors. International Journal of Information Management, 2017, 37(6): 673-683.

[148] Hu Y H, Chen K C. Predicting hotel review helpfulness: The impact of review visibility, and interaction between hotel stars and review ratings. International Journal of Information Management, 2016, 36(6): 929-944.

[149] Ali O, Crvenkovski P, Johnson H. Using a business intelligence data analytics solution in healthcare. The 7th IEEE Annual Information Technology, Electronics and Mobile Communication Conference (IEEE IEMCON), Vancouver, BC, Canada, 2016.

[150] Rafailidis D. A multi-latent transition model for evolving preferences in recommender systems. Expert Systems with Applications, 2018, 104: 97-106.

[151] Leonardo V, David M H, Mauro C, et al. An artificial intelligence system for predicting customer default in e-commerce. Expert Systems with Applications, 2018, 104: 1-21.

[152] Thambo N, Nelishia P. Comparison of a genetic algorithm to grammatical evolution for automated design of genetic programming classification algorithms. Expert Systems with Applications, 2018, 104: 213-234. 


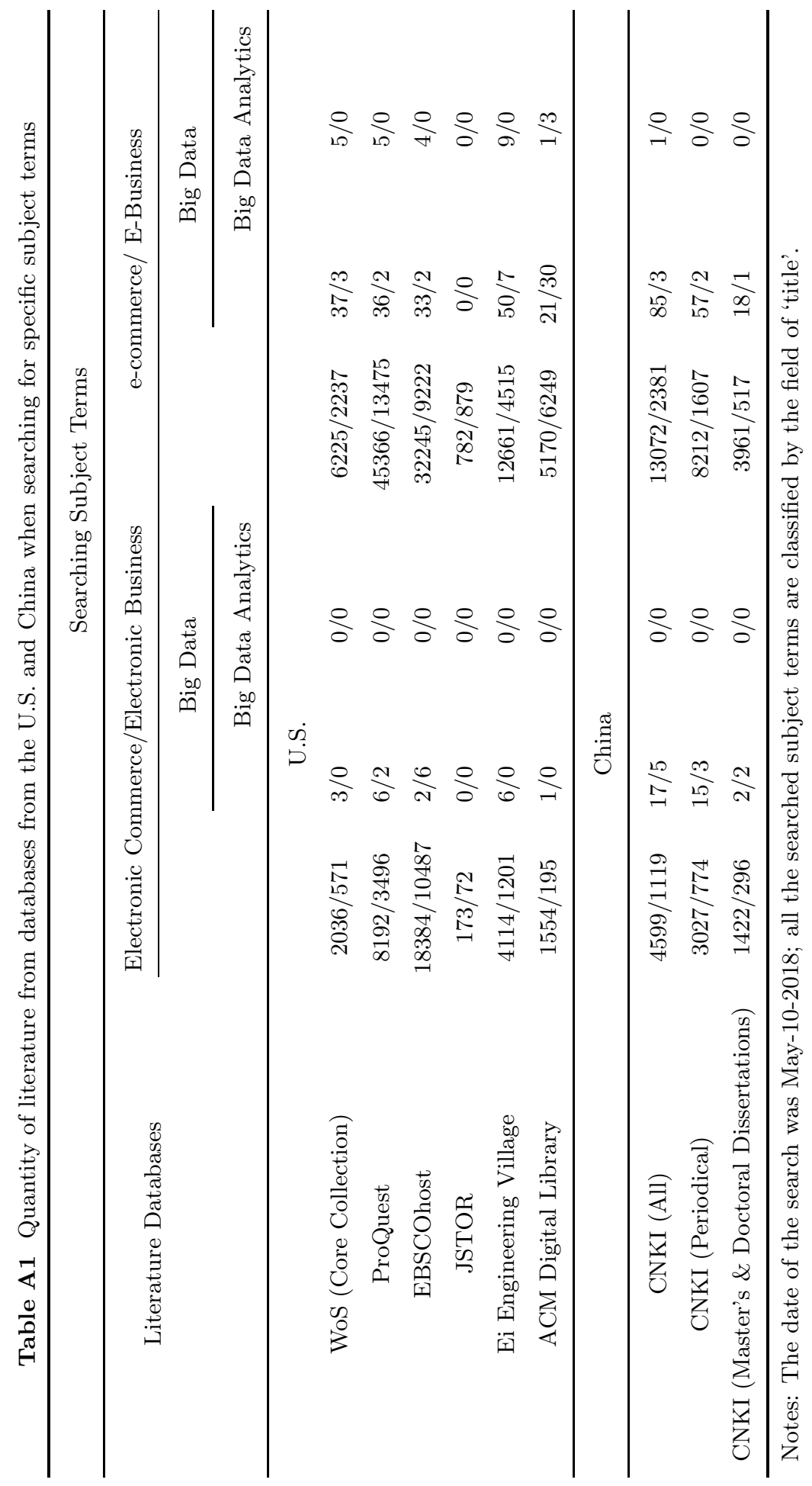




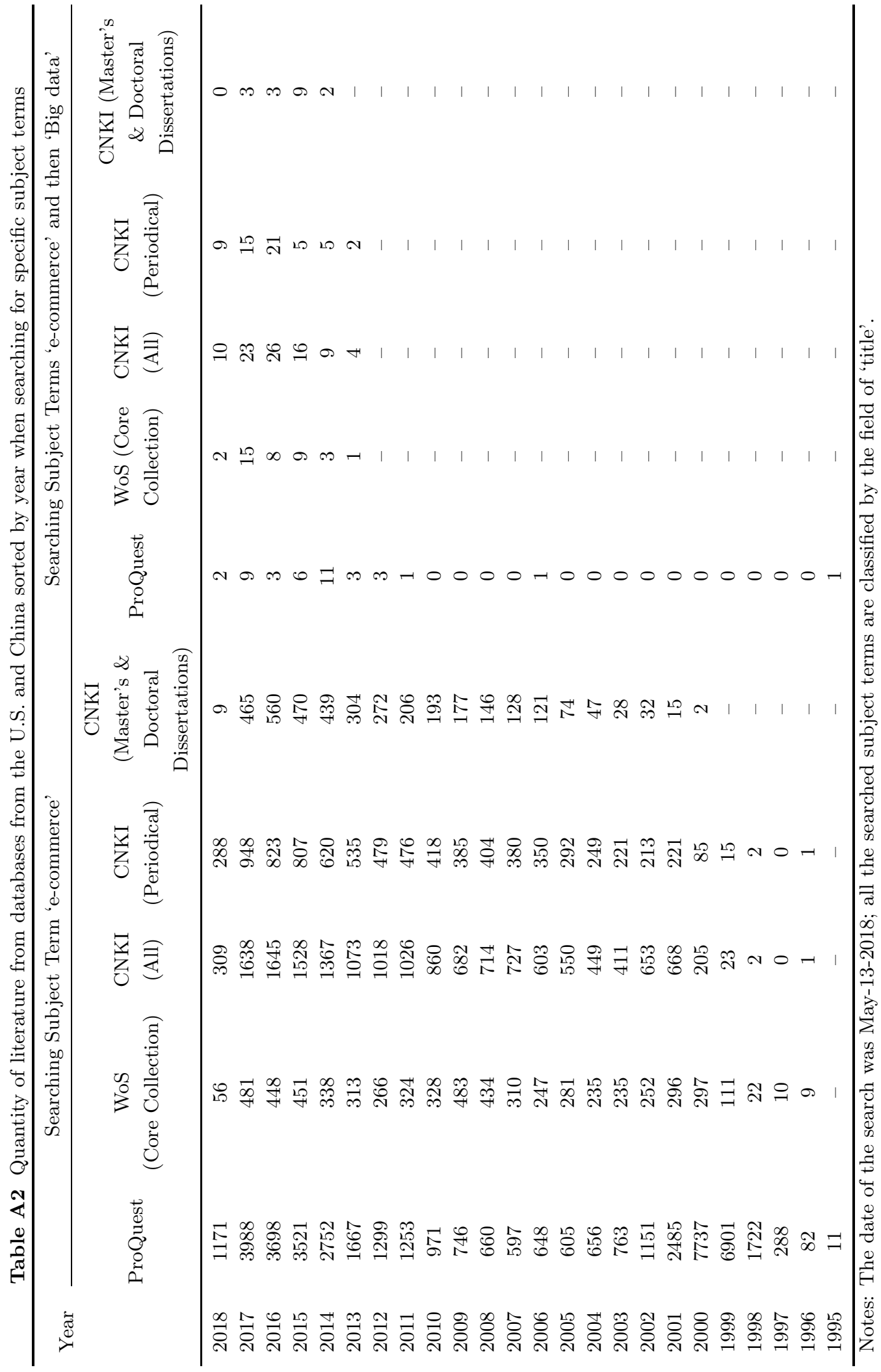




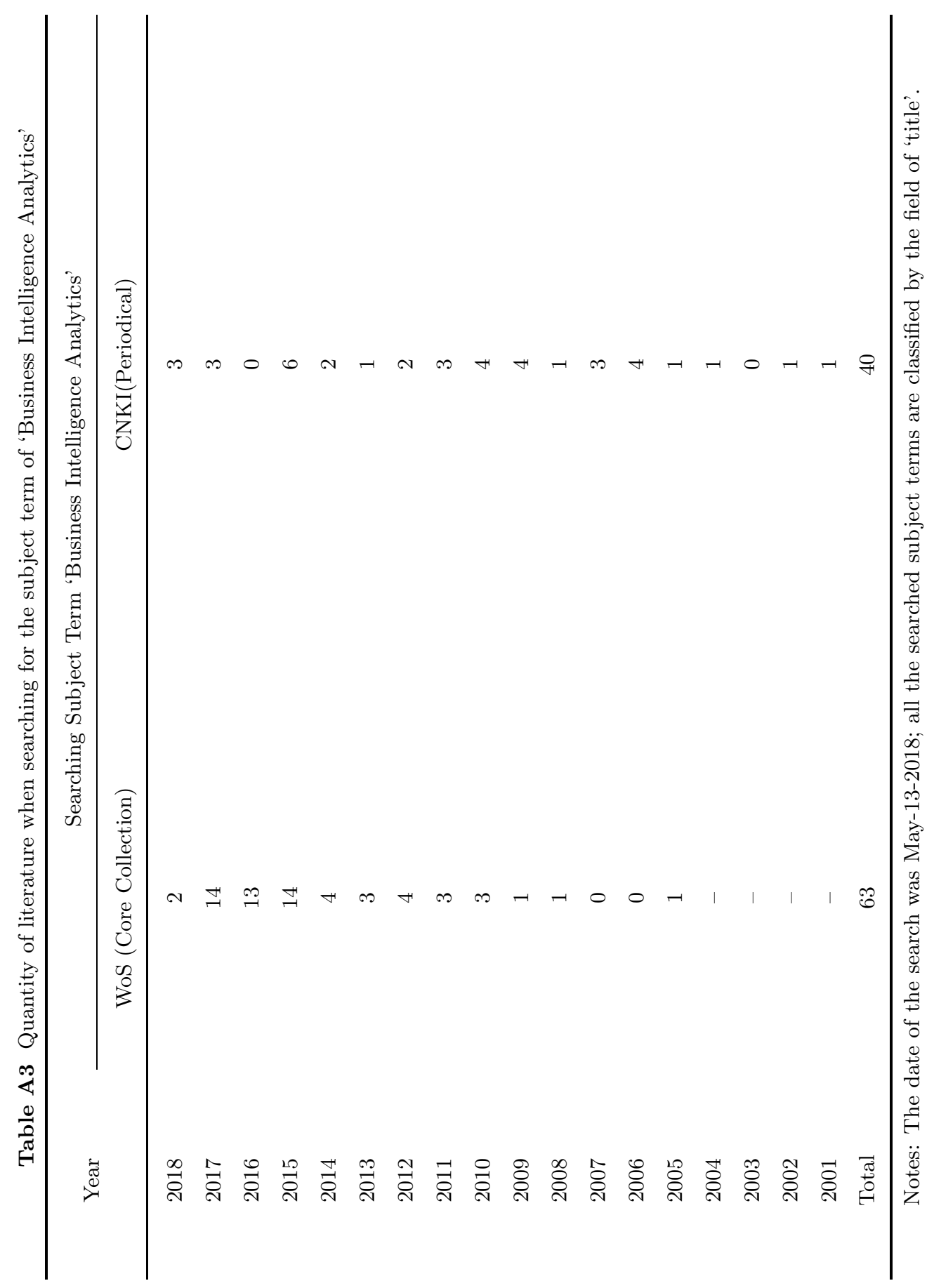




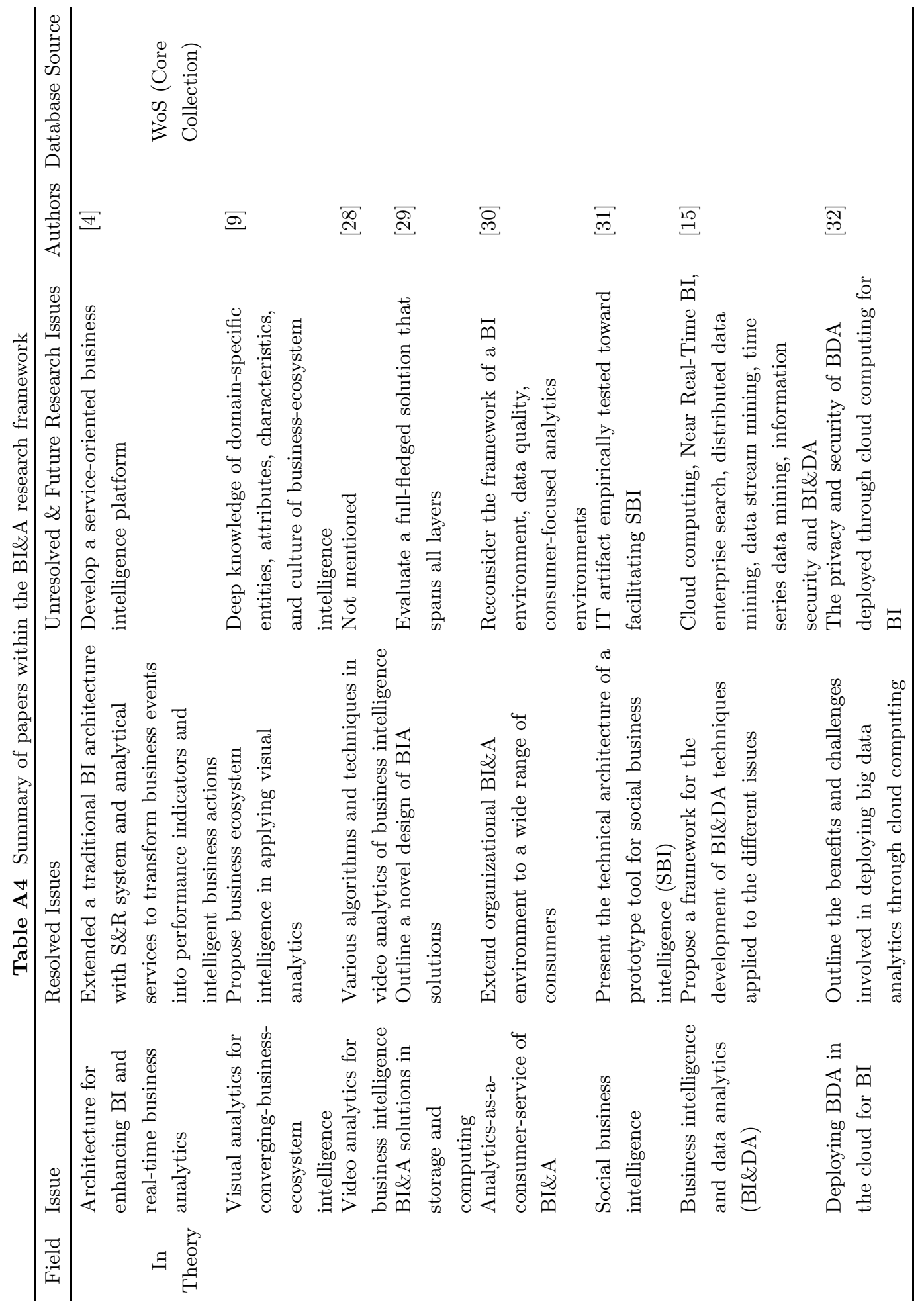




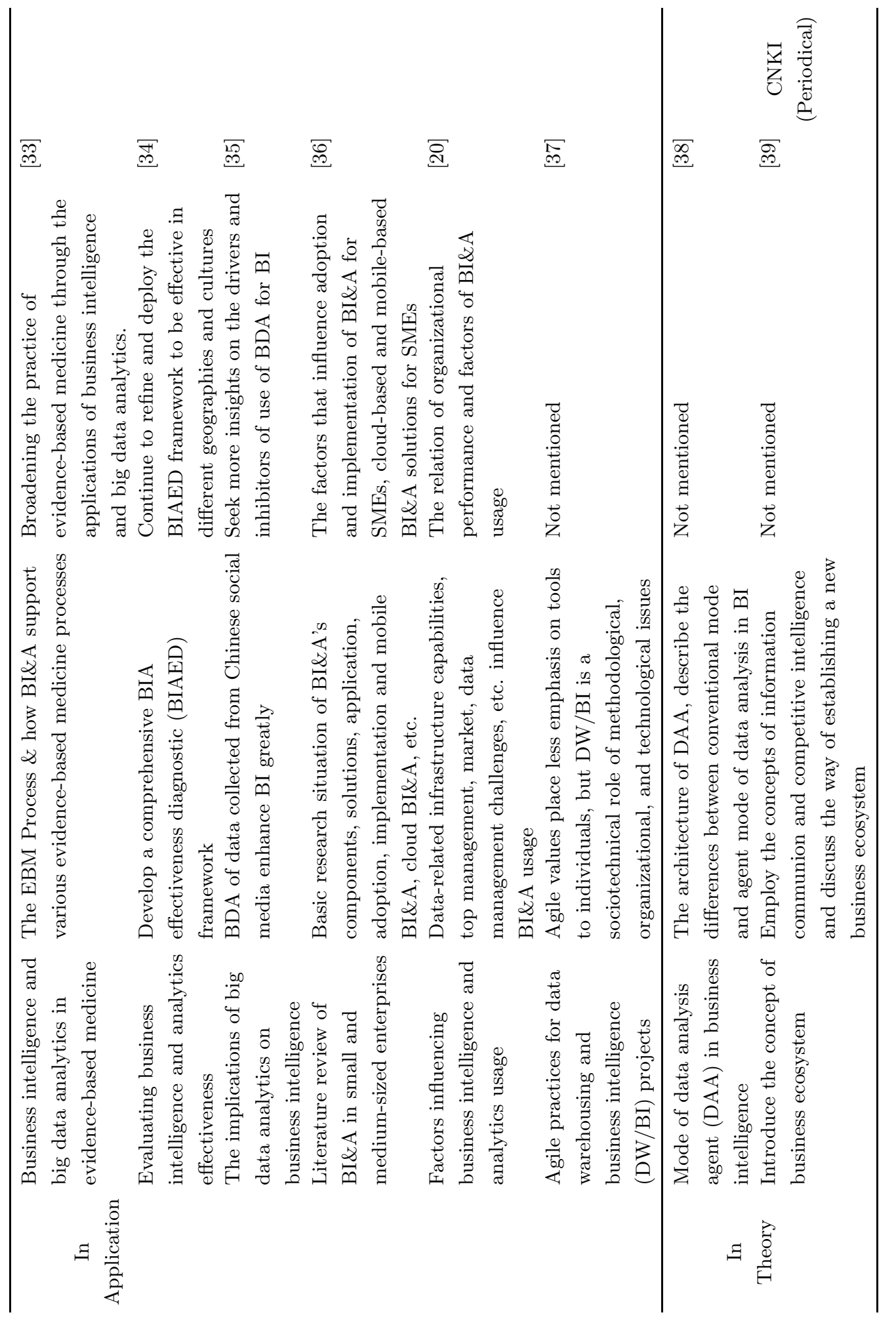




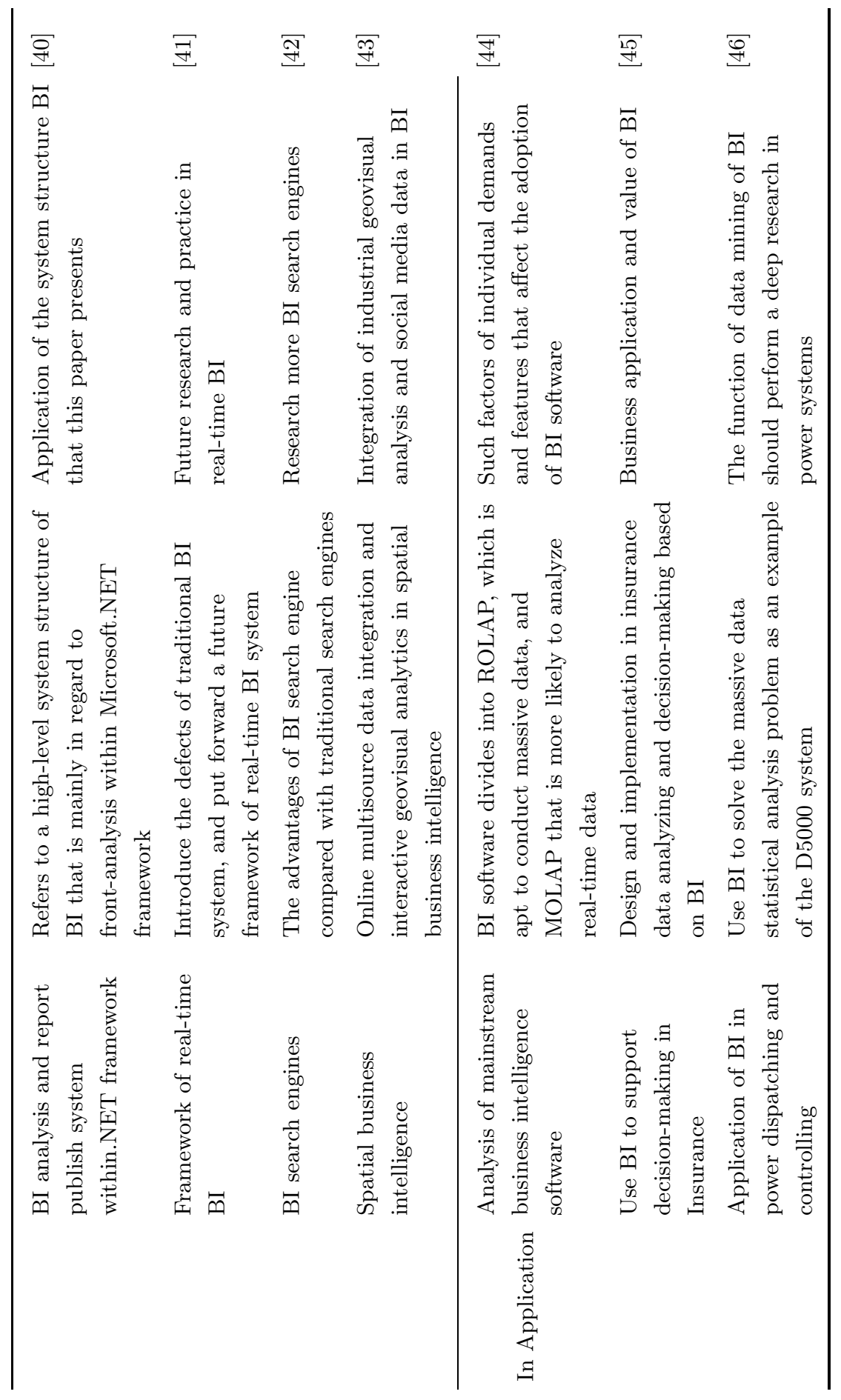




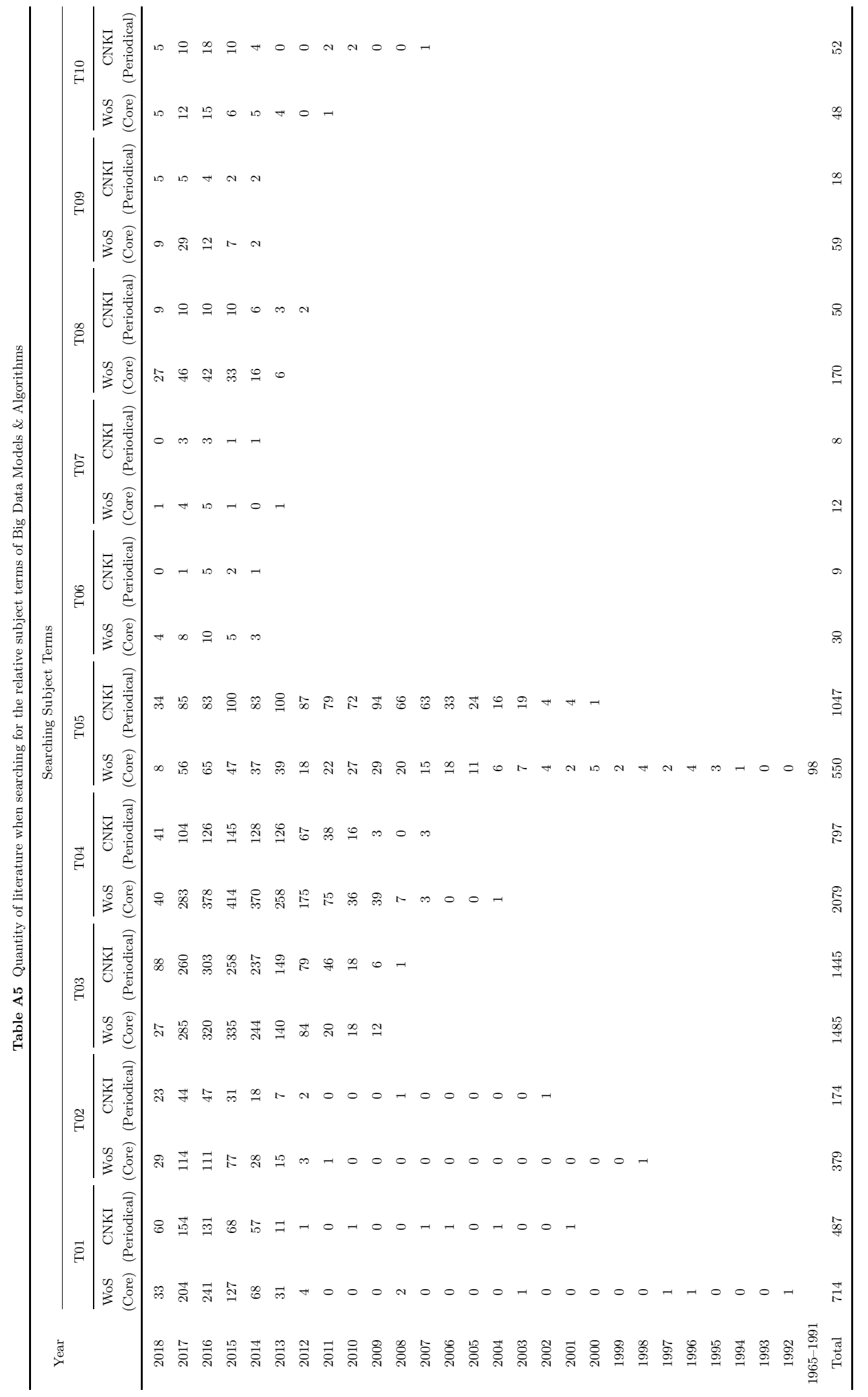




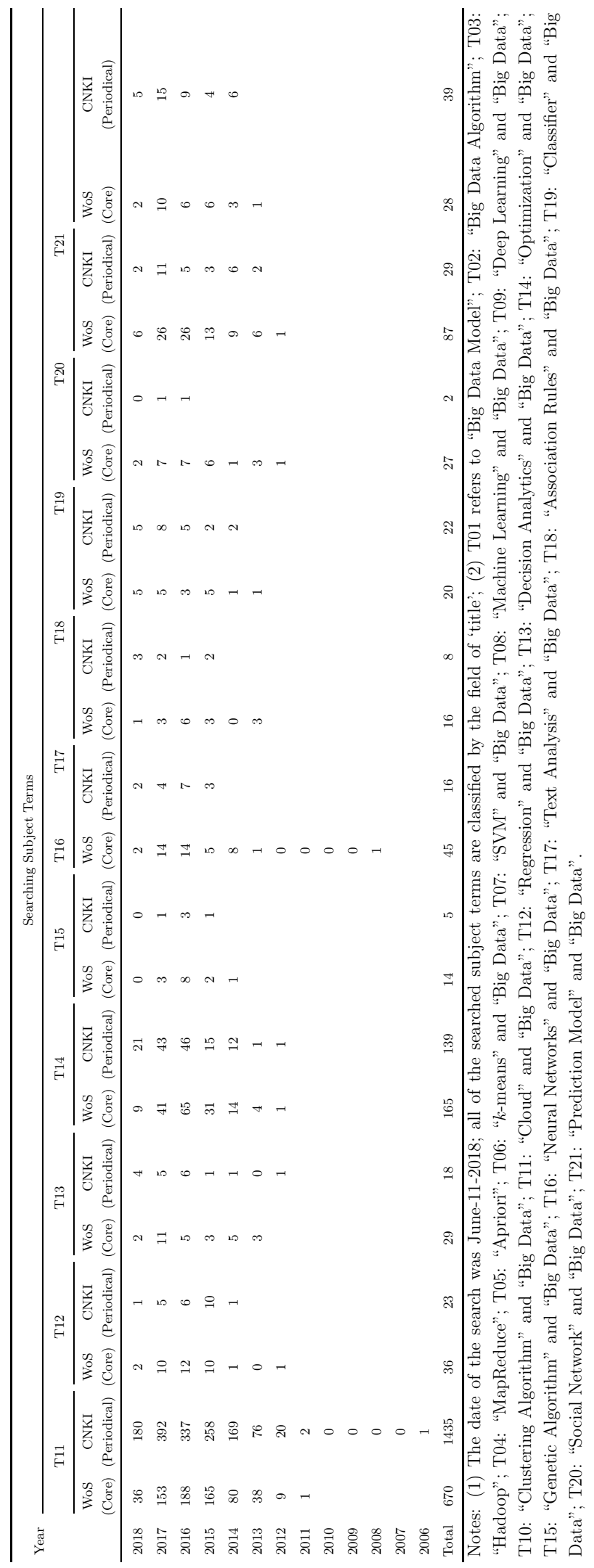




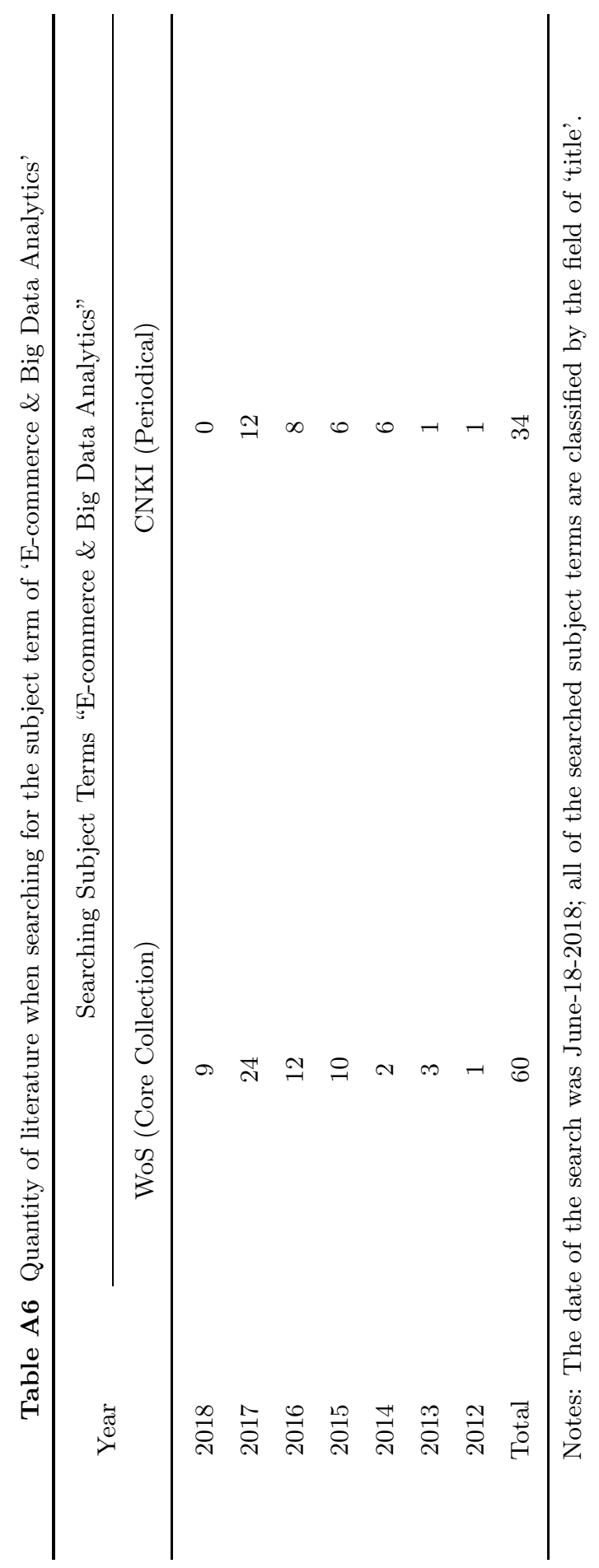




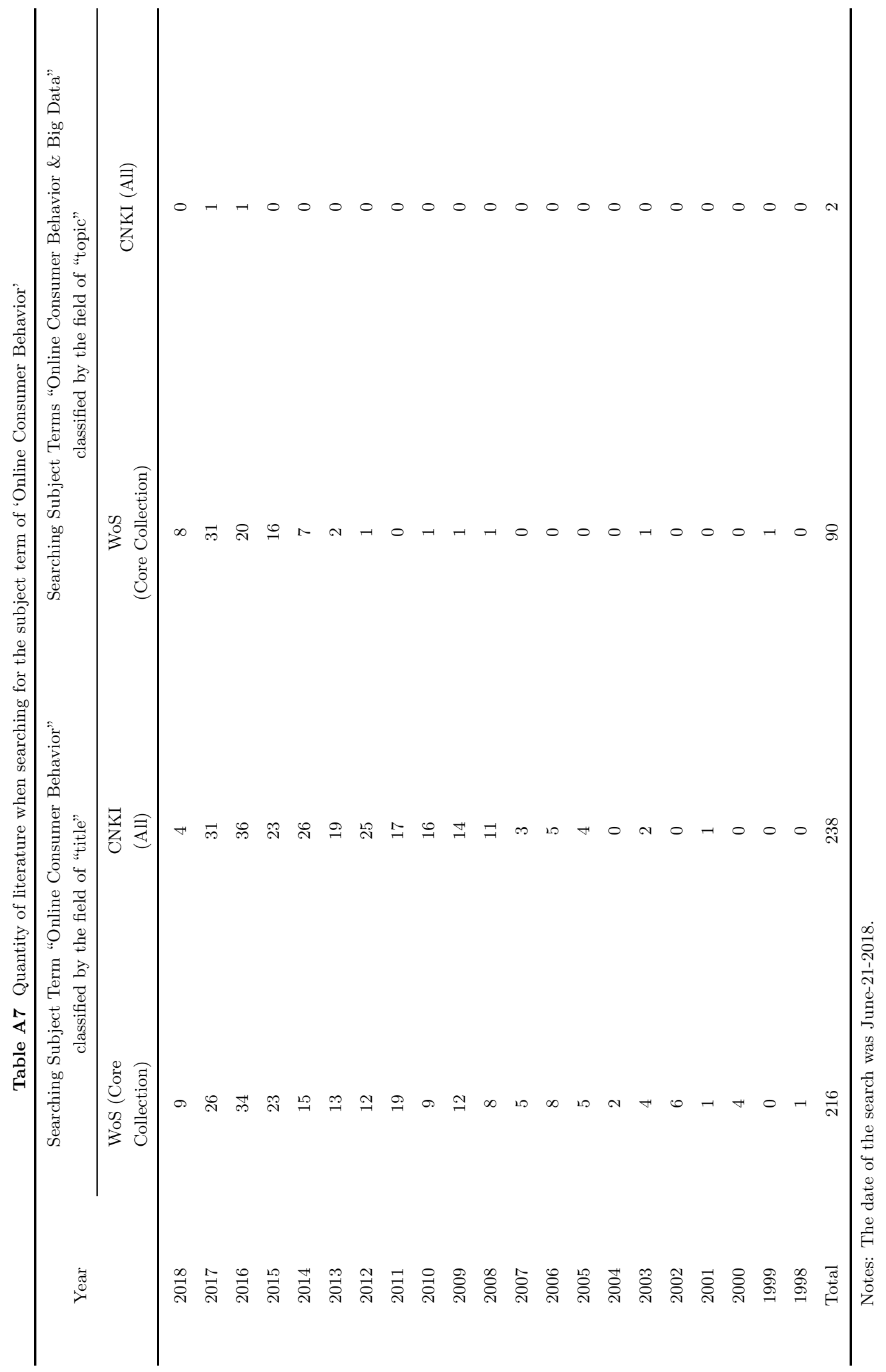




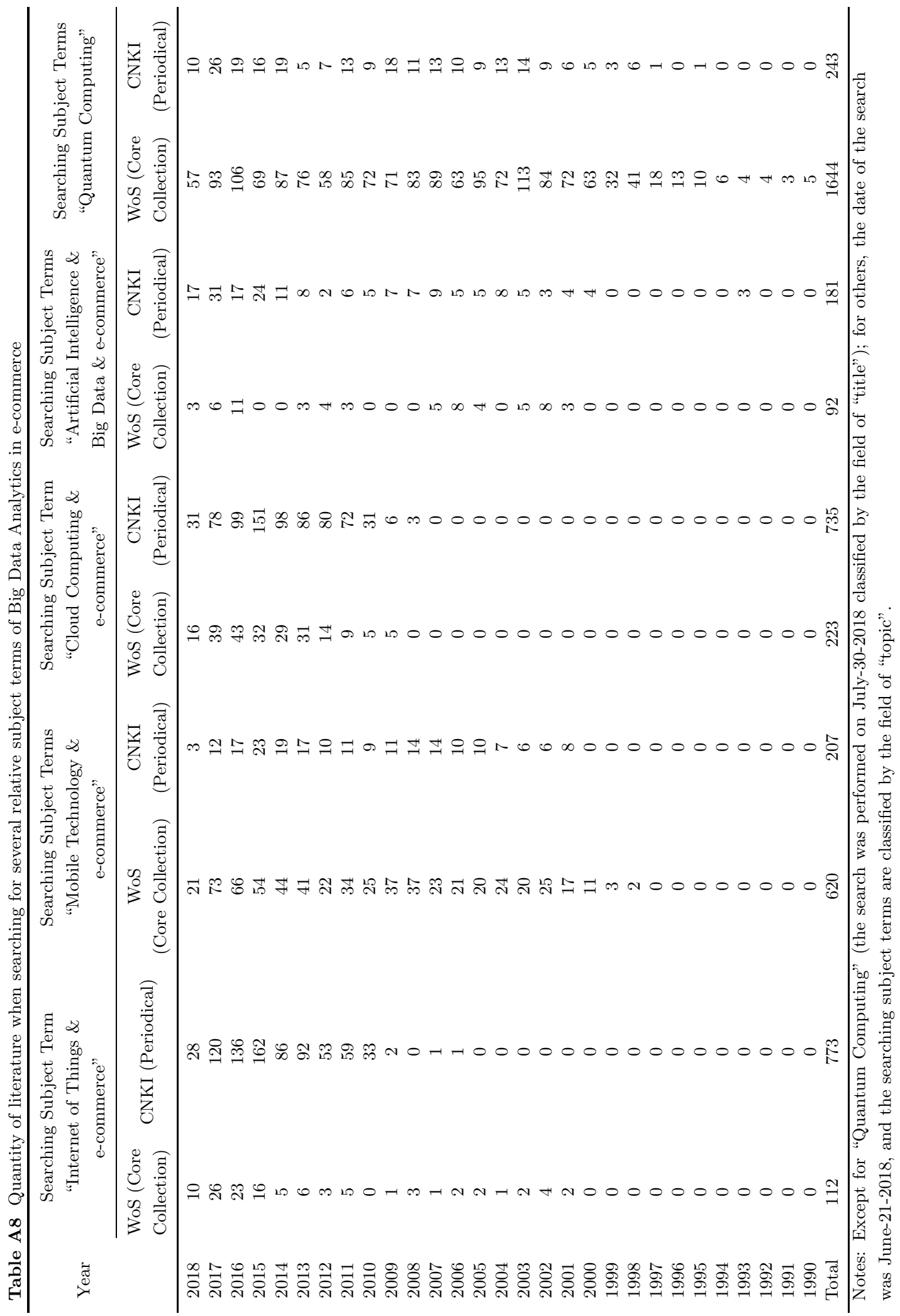

